\title{
3D Direct Writing Fabrication of Electrodes for Electrochemical
}

\section{Storage Devices}

Min Wei, ${ }^{\text {a,fl }}$ Feng Zhang, ${ }^{\text {, }}$ Il Wei Wang, ${ }^{\text {a }}$ Paschalis Alexandridis, ${ }^{a}$ Chi Zhou,,${ }^{*}$ and Gang Wu ${ }^{\text {a, }}$

${ }^{a}$ Department of Chemical and Biological Engineering, University at Buffalo, The State

University of New York, Buffalo, New York 14260, United States

${ }^{\mathrm{b}}$ Department of Industrial and Systems Engineering, University at Buffalo, The State

University of New York, Buffalo, New York 14260, United States

II These two authors contributed equally.

Corresponding authors: chizhou@buffalo.edu (C. Zhou) and gangwu@buffalo.edu (G. Wu)

\section{GRAPHICAL ABSTRACT:}

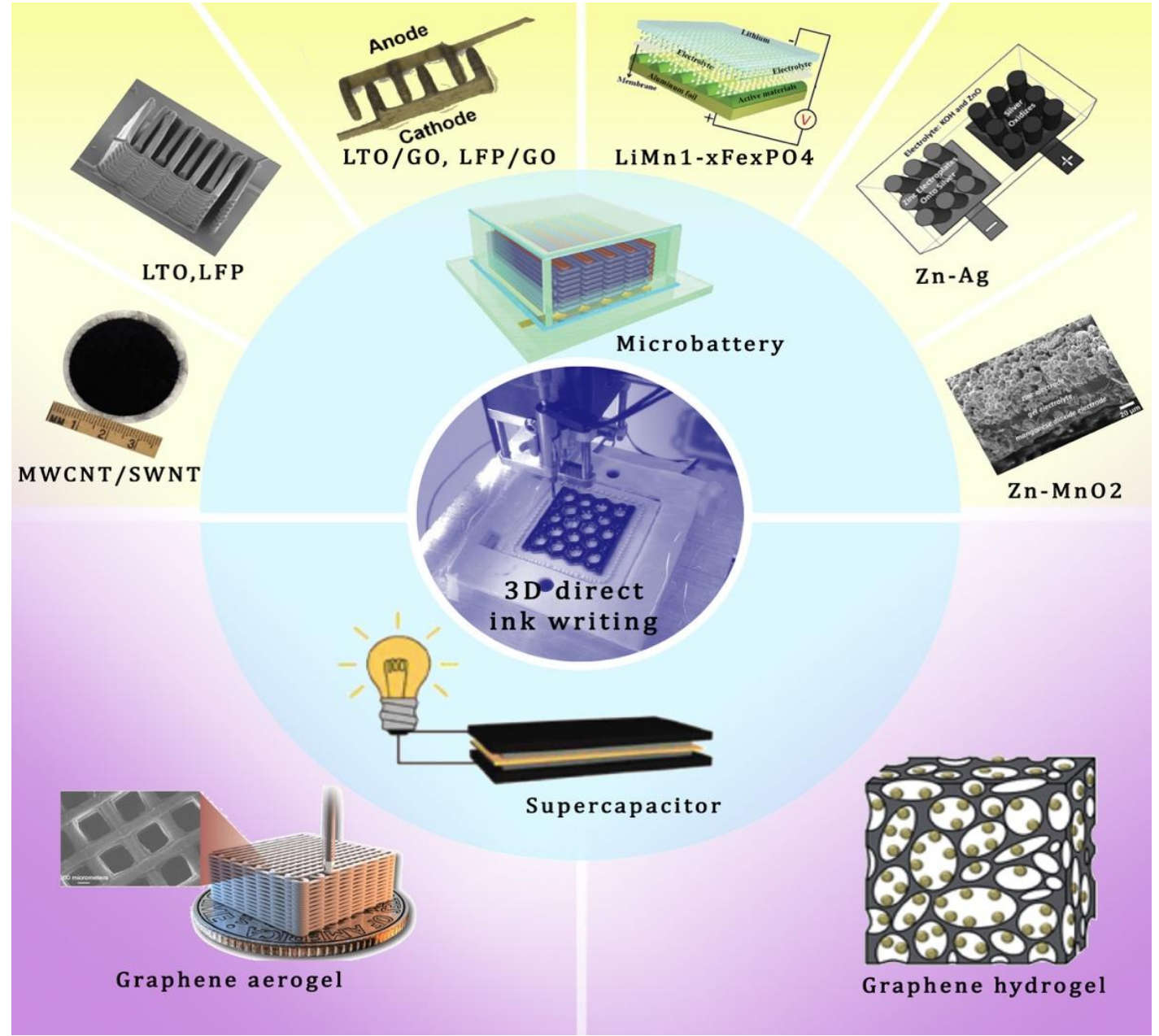


Abstract: Among different printing techniques, direct ink writing is commonly used to fabricate 3D battery and supercapacitor electrodes. The major advantages of using the direct ink writing include effectively building 3D structure for energy storage devices and providing higher power density and higher energy density than traditional techniques due to the increased surface area of electrode. Nevertheless, direct ink writing has high standards for the printing inks, which requires high viscosity, high yield stress under shear and compression, and well-controlled viscoelasticity. Recently, a number of 3D-printed energy storage devices have been reported, and it is very important to understand the printing process and the ink preparation process for further material design and technology development. We discussed current progress of direct ink writing technologies by using various electrode materials including carbon nanotube-based material, graphene-based material, LTO $\left(\mathrm{Li}_{4} \mathrm{Ti}_{5} \mathrm{O}_{12}\right)$, LFP $\left(\mathrm{LiFePO}_{4}\right), \mathrm{LiMn}_{1-\mathrm{x}} \mathrm{Fe}_{\mathrm{x}} \mathrm{PO}_{4}$, and $\mathrm{Zn}$-based metallic oxide. Based on achieve electrochemical performance, these 3D-printed devices deliver performance comparable to the energy storage device fabricated using traditional methods still leaving large room for further improvement. Finally, perspectives are provided on the potential future direction of 3D printing for all solid-state electrochemical energy storage devices.

Keywords: 3D printing; direct ink writing; nanomanufacturing; supercapacitors; batteries

\section{Introduction}

\subsection{Electrochemical Energy Storage Devices}

Energy storage technologies, including thermal storage, mechanical storage, electrochemical storage, and chemical storage (i.e., hydrogen storage) play a critical role in converting energy forms that are difficult to store to more economical and convenient energy forms [1]. Among energy storage technologies, electrochemical energy storage is important to build sustainable 
energy systems which can convert chemical energy to electric energy and reverse by applying electron and ion transfer in electrodes [2]. Electrochemical energy storage systems include supercapacitors, batteries, and their hybrid devices [3]. These devices can be used in starting, lighting and ignition of electric vehicles, spacecrafts, pacemakers, etc. [4]. However, as the U.S. Defense Logistics Agency pointed out, current electrochemical energy storage devices can either provide high power density or high energy density but not both [5].

Supercapacitors and batteries are both composed of electrodes and electrolyte. The electrodes are referred to an anode and a cathode in the electrochemical cell. During the discharge, the anode is the terminal where electrons flow out, while the cathode is the terminal where electrons flow into. The electrolyte plays the role of a medium for ion transfer between two electrodes [9]. Table 1 shows that supercapacitors have several advantages, such as long cycle life (>10k cycles), rapid charging-discharging rate at relative high power density (10k W $\mathrm{kg}^{-1}$ ) and operate in a safe manner [10-12]. However, current supercapacitors suffer from a wellknown disadvantage of poor energy density which is generally around 5-10 $\mathrm{Wh} \mathrm{kg}^{-1}$ [13]. Compared to supercapacitors, batteries involve faradic oxidation and reduction process. The electroactive reagents release charges which can flow between two electrodes once different electrode potential is applied [14]. Supercapacitors, such as the electrochemical double layer capacitor, do not involve any electrochemical reaction with charge transfer, but only the electrostatic force between charged ions and electrodes [9]. Batteries have relative high energy density between 30 and $170 \mathrm{Wh} \mathrm{kg}^{-1}$ [13]. However, due to the low power density, batteries normally take 2-6 $\mathrm{h}$ to recharge for plug-in hybrid vehicles [13]. 
Table. 1 Comparison of the properties of batteries and supercapacitors. With reprint permission from Ref [6-8].

\begin{tabular}{|c|c|c|c|c|c|c|}
\hline \multicolumn{2}{|c|}{ Types } & $\begin{array}{l}\text { Rated } \\
\text { Voltage } \\
\text { (V) }\end{array}$ & $\begin{array}{c}\text { Energy } \\
\text { Density } \\
(\mathrm{Wh} \\
\left.\mathrm{kg}^{-1}\right)\end{array}$ & $\begin{array}{c}\text { Power } \\
\text { Density } \\
\left(\mathrm{W} \mathrm{kg}^{-}\right. \\
1)\end{array}$ & $\begin{array}{l}\text { Energy } \\
\text { efficiency } \\
(\%)\end{array}$ & $\begin{array}{c}\text { Lifetime } \\
\text { (Charge/discharge } \\
\text { cycles) }\end{array}$ \\
\hline \multirow{3}{*}{ Batteries } & $\begin{array}{l}\text { Lead-acid } \\
\text { batteries }\end{array}$ & 2 & 30 & 180 & $85-90$ & $1,200-1,800$ \\
\hline & $\begin{array}{l}\text { Nickel-based } \\
\text { batteries }\end{array}$ & 1.2 & $50-80$ & $\begin{array}{c}50- \\
1,000\end{array}$ & $65-80$ & 1,500 \\
\hline & $\begin{array}{l}\text { Lithium-based } \\
\text { batteries }\end{array}$ & 3.7 & $80-150$ & $\begin{array}{l}500- \\
2,000\end{array}$ & $90-100$ & $600-1,500$ \\
\hline \multirow[t]{2}{*}{ Supercapacitors } & $\begin{array}{l}\text { Electrochemical } \\
\text { double layer } \\
\text { supercapacitors } \\
\text { (ECDL) }\end{array}$ & $1-3$ & 5 & 10,000 & $85-98$ & 500,000 \\
\hline & Pseudocapacitors & $1.2-1.5$ & 10 & 10,000 & 95 & 700,000 \\
\hline
\end{tabular}

\subsection{Two-Dimensional (2D) structure and Three-Dimensional (3D) structure of Electrode}

With the purpose of improving the power performance and the safety of electrochemical energy storage devices, 3D structure devices are being pursued for supercapacitors and batteries in recent years. Compared with the traditional 2D planar structure of electrode for electrochemical energy storage devices, 3D structure is strongly recommended because it provides shorter diffusion pathways and smaller resistance during the ion transport process [15]. Additionally, a 3D structure also can potentially double the energy density by creating porous structure and efficiently using the limited space available [16]. The mathematic relationship between power density and the physical properties for 2D structure devices can be expressed as equation (1):

$$
P D \propto \frac{V \times \lambda \times A}{L}
$$

where $P D$ is power density, $V$ is voltage, $\lambda$ is ion conductivity, $A$ is surface area and $L$ is ion transport length. In this equation, voltage and ion conductivity are related to the intrinsic material 
properties of the electrodes and the electrolyte, while the surface area and the transport length are determined by the structure of the devices [5]. Conventionally, the electrodes on the 2D devices are designed to be folded, wound or stacked. In order to increase the energy density of devices, the traditional way is to increase the thickness of the electrodes. However, this will cause the power density to decrease due to the increased ion transport length [5]. Moreover, traditional battery designs with 2D structure require a large footprint area in order to generate high capacity [17]. Therefore, the power density and the energy density exhibit an inversely proportional relationship in 2D structure. Besides, the equation (2) which is presented below demonstrates the relationship between specific energy and porosity of the electrodes [18],

$$
E=\frac{(1-I) I T-\frac{I^{3} T^{2}}{2 \delta^{1.5}(1-\delta)}}{\frac{\rho_{r} L_{r}}{\rho_{s} L_{s}}+1+\frac{L_{+}}{L_{s}}\left[\delta+\frac{\rho_{+}}{\rho_{s}}(1-\delta)\right]} \quad \text { and } \quad T=\frac{U k_{s} t_{d}}{q_{+} L_{s}^{2}}
$$

Where $E$ is specific energy, $I$ is the current density, $\delta$ is porosity of the electrode, $\rho_{r} L_{r}$ is the mass of current collector or other sheets between the cells, $\rho_{s}$ is the density of separator, $L_{s}$ is the thickness of separator, $L_{+}$is the thickness of the electrode, $\rho_{+}$is the density of the electrode material, $U$ is the open-circuit potential, $k_{s}$ is the separator conductivity, $t_{d}$ is discharge time and $q_{+}$is the capacity per unit volume of solid material which including active material, conductive additives and binder. From this equation, for a given discharge time, open-circuit potential and electrode capacity density, with other parameters are supposed to be fixed, porous electrodes can be designed to increase the specific energy of batteries. By ingeniously manipulating the $3 \mathrm{D}$ porous structure, the surface area increases without increasing the transport length, which offers a potential opportunity to improve the power density and energy density at the same time. A qualitative comparison between 2D thin film battery and 3D nano-architectures battery is shown 
in Table 2. As noted in the table, two main advantages of 3D structure electrode for electrochemical energy storage devices are an increase in energy density within a small areal footprint and an increase in power density by decreasing transport path of ions in the electrolyte [20].

Table 2. Comparison between general attributes of $2 \mathrm{D}$ thin film battery and 3D nanoarchitectures battery. With reprint permission from Ref [19].

\begin{tabular}{llllll}
\hline & $\begin{array}{l}\text { Solid-state } \\
\text { ion diffusion } \\
\text { path-length }\end{array}$ & $\begin{array}{l}\text { Effective } \\
\text { active mass } \\
\text { utilization }\end{array}$ & $\begin{array}{l}\text { Energy } \\
\text { density }\end{array}$ & $\begin{array}{l}\text { Power } \\
\text { density }\end{array}$ & $\begin{array}{l}\text { Areal } \\
\text { footprint }\end{array}$ \\
\hline 2D thin film & $>1 \mathrm{um}$ & Low & High & Moderate & Large \\
\hline $\begin{array}{l}\text { 3D Nano- } \\
\text { architectures }\end{array}$ & $<100 \mathrm{~nm}$ & High & Moderate & High & Small \\
\hline
\end{tabular}

\subsection{Direct Ink Writing (DIW)}

3D structure energy storage devices show some potential advantages as explained above. Currently, several strategies have been employed to accurately prepare 3D architectures including direct ink writing (DIW) [21], direct laser writing (DLW) [22], interference lithography (IL) [23], phase-mask lithography (PML) [24], and colloidal self-assembly (CSA) [25]. Direct ink writing is one of the most popular 3D printing methods applied in energy device printing area, because of the low cost, material flexibility and the ability to construct arbitrary 3D architectures without additional expensive tooling, lithographic masks or dies [21, 26]. Usually, an initial investment of direct ink writing technique is less than $\$ 1,000$ which included a simple desktop 3D printer, heated bed, air-powered dispenser and micro-nozzle [27]. The term 'direct ink writing' depicts fabrication methods where a computer can control the translation stage and the pattern generating device, such as ink-deposition nozzle, to create materials with a specific 
composition and architecture [26]. In principle, direct ink writing techniques are based on the deposition of inks with a desired rheological behavior, e.g., nanoparticle-, colloid-, or organicbased inks to build patterns in layer-by-layer fashion [26]. After deposition, the patterns usually become solid through the evaporation of solvents, chemical changes (e.g., cross-linking of polymers) or cooling [28]. As shown in Fig. 1, the direct ink writing techniques include: (1) continuous filament approaches, such as robocasting [29], fused deposition [30], and micropen writing [31]; (2) droplet-based approaches, such as ink-jet printing [32], hot-melt printing [33] and 3D printing. Each printing scenario benefits from its advantages but also suffers from its drawbacks. A comparison of each printing scenario is shown in Table 3. For continuous filament writing approach, the ink is extruded continuously from a fine cylindrical nozzle with a diameter ranging from 0.1 to $250 \mu \mathrm{m}$ to make a filamentary element [34, 35]. Fig. 1 demonstrates there are a number of ink materials which can be printed into different 3D structures by using continuous filament approaches. For the droplet-based approach, the ink is deposited drop by drop as needed. One of the big challenges is the ink preparation due to the specific rheological property requirement. The properties of inks are directly affected by material preparation, printing strategy and architectural design. A well printable ink is usually composed of polymeric or particulate species which can be easily dissolved or suspended in a liquid, ultraviolet- (UV-) curable resins which are polymerized upon printing, or wax-based materials [36]. Specific parameters, such as appropriate ink viscosity, high yield stress under shear and compression, and well-controlled viscoelastic properties should be met for printable ink. Typically, the ink viscosity and filament diameter for continuous filament writing are controlled as $10^{2}-10^{6} \mathrm{mPa} \cdot \mathrm{s}$ and $1 \mu \mathrm{m}-1 \mathrm{~mm}$, respectively. Furthermore, the corresponding values of droplet-based printing are kept as $2-20 \mathrm{mPa} \cdot \mathrm{s}$ and $10-30 \mu \mathrm{m}$ [36]. Thus, only delicately prepared inks can flow through 
the deposition nozzle smoothly, and minimize drying-induced shrinkage after the deposition [21]. Different macro and micro structures of materials that are prepared by droplet-based writing are also presented in Fig.1.

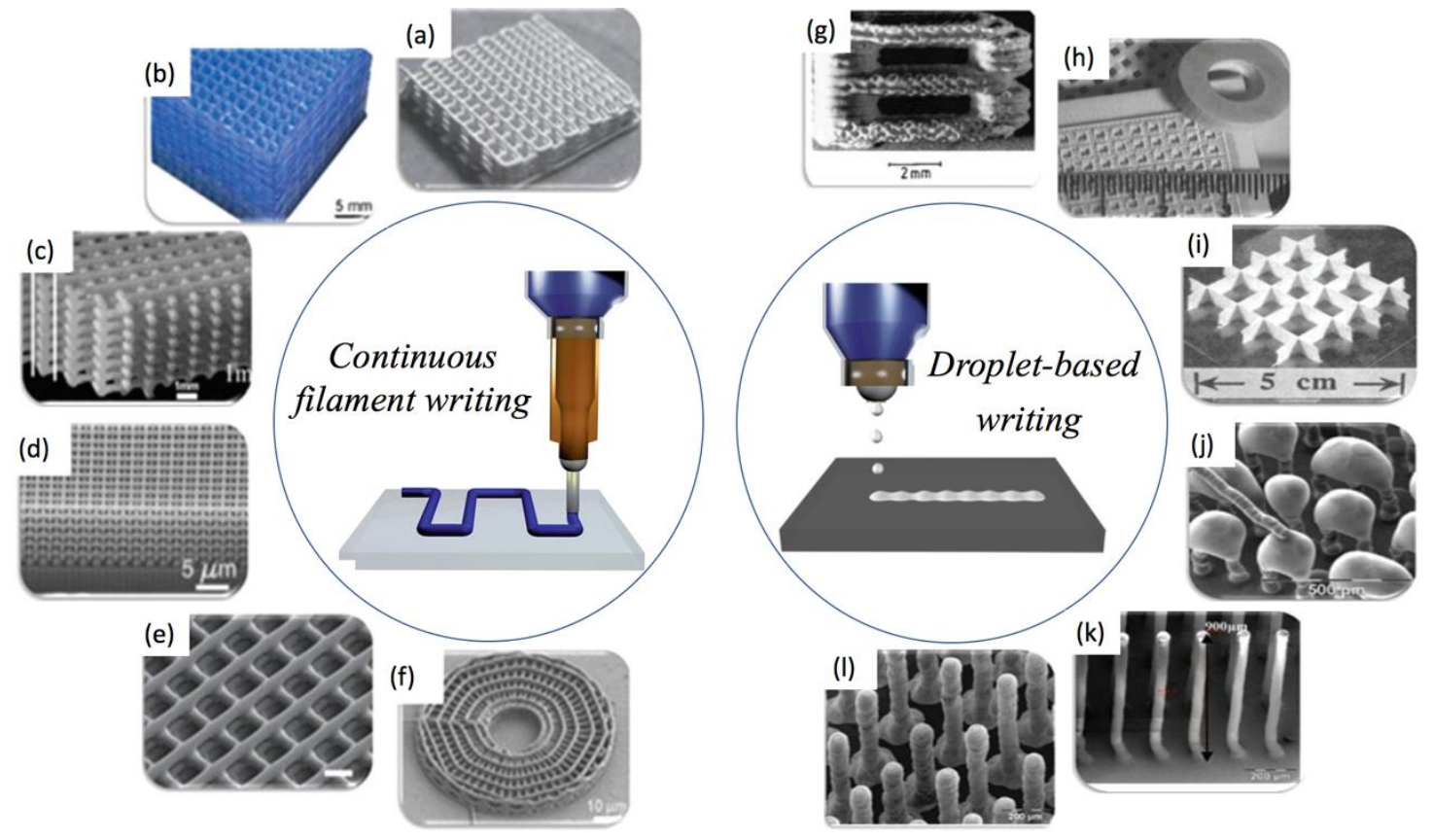

Fig. 1. Continuous writing, (a) Biomaterial inks, (b) Fugitive organic inks, (c) Colloidal inks, (d) Sol-gel inks, (e) Hydrogel inks, (f) Polyelectrolyte inks; Droplet-based writing, (g) 3D ceramic components, (h) Unfired ceramic, (i) Structure made via 3D printing, (j) 3D micro-periodic structures made via sol-gel inks, (k) SEM micrographs of 3D pHEMA scaffolds, (l) 3D radial array. With reprint permission from Ref [35]. 
Table 3. Comparison of different ink-writing techniques. With reprint permission from Ref [26, 34].

\begin{tabular}{|c|c|c|c|}
\hline \multicolumn{2}{|c|}{ Techniques } & \multirow{2}{*}{$\begin{array}{l}\text { Ink Design } \\
\text { Concentrated colloidal gel }\end{array}$} & $\begin{array}{l}\text { Minimum } \\
\text { Printed } \\
\text { Feature Size }\end{array}$ \\
\hline \multirow{7}{*}{$\begin{array}{l}\text { Continuous } \\
\text { Approaches }\end{array}$} & \multirow[t]{4}{*}{ Robocasting } & & $\begin{array}{l}200 \quad \mu \mathrm{m} \\
\text { diameter }\end{array}$ \\
\hline & & Concentrated nanoparticle gel & $\begin{array}{l}100 \\
\text { diameter }\end{array}$ \\
\hline & & Viscous polymer solution & $\begin{array}{l}200 \\
\text { diameter }\end{array}$ \\
\hline & & $\begin{array}{l}\text { Concentrated polyelectrolyte } \\
\text { complexes }\end{array}$ & $<1 \mu \mathrm{m}$ \\
\hline & \multirow{2}{*}{$\begin{array}{l}\text { Fused } \\
\text { Deposition }\end{array}$} & Thermoplastic polymer melt & $\begin{array}{l}100 \\
\text { diameter }\end{array}$ \\
\hline & & $\begin{array}{l}\text { Particle-filled polymer melt (max. } \\
\text { solids } \sim 50 \% \text { ) }\end{array}$ & $\begin{array}{l}100 \\
\text { diameter }\end{array}$ \\
\hline & $\begin{array}{l}\text { Micropen } \\
\text { Writing }\end{array}$ & $\begin{array}{l}\text { Concentrated, shear-thinning } \\
\text { colloidal fluid }\end{array}$ & $\begin{array}{l}25 \\
\text { diameter }\end{array}$ \\
\hline \multirow{4}{*}{$\begin{array}{l}\text { Droplet-based } \\
\text { Approaches }\end{array}$} & Ink-jet Printing & Dilute fluid & $\begin{array}{l}20 \mu \mathrm{m} \text { lateral, } \\
100 \mathrm{~nm} \text { height }\end{array}$ \\
\hline & Hot-melt & Colloid-filled wax (max. solids & $70 \mu \mathrm{m}$ lateral, \\
\hline & Printing & $\sim 40 \%)$ & $<1 \mu \mathrm{m}$ height \\
\hline & 3D Printing & $\begin{array}{l}\text { Binder solution printed on } \\
\text { powder bed }\end{array}$ & $\begin{array}{l}170 \mu \mathrm{m} \text { lateral, } \\
45 \mu \mathrm{m} \text { depth }\end{array}$ \\
\hline
\end{tabular}

A broad range of materials can be used in 3D printing by the direct ink writing techniques, including colloidal gels/suspensions, polymers, ceramics, metal alloys, electronically functional materials, and waxes containing a number of ingredients such as powder, nanoparticles, surfactants, organic precursors etc. [28, 37]. Recently, carbon-based materials have been widely investigated as electrode for 3D structure energy storage devices, such as carbon nanotubes (CNTs), carbide derived carbons, carbon nanofibers (CNFs), graphene oxide (GO), and graphene [9]. Carbon-based inks are typically prepared in volatile solutions which includes carbon fibers such as carbon blacks and GO, solvent, polymers and other additives. Inks prepared by carbon blacks always require additional polymers to adjust the viscosity of the inks in order to achieve 
the proper printability [38]. In contrast, graphene-based materials, which exhibit large specific surface area, great electrical conductivity, chemical stability and environment-friendliness, are extensively used as active materials for electrodes [39]. There are different synthesis methods to prepare graphene-based materials, including chemically exfoliated graphene oxide [40], chemical vapor deposition (CVD) [41], ethanol-CVD [42]. However, the assembly of graphene into applicable monolith is a big challenge. Unsuccessful assembly process would cause problems such as restacking and aggregation of graphene sheets, which would narrow the ion and electron transport channels and reduce the ion-accessible surfaces, leading to a drastic decrease of capacitive performance [39]. In order to overcome these shortcomings, several graphene-based materials with 3D structure, for instance, hydrogels, aerogels, sponges and porous films [43-46] have been proposed since they can provide a network of interconnected pores for 3D structure devices [47].

3D printing is able to print graphene hydrogel and aerogel for electrochemical energy storage devices [48]. Hydrogel can absorb significant amounts of water (over 90\%) without dissolving [49]. Hydrogel has attracted significant attention due to its properties of great flexibility and light weight. Aerogel is the other most popular 3D graphene-based material to fabricate electrodes for supercapacitors and batteries due to its very high specific surface area for ion accessibility. Aerogel is a synthetic porous material and it is flexible to be fabricated from different types of materials, such as metals, carbons and polymers [50]. Besides, the porosity, pore structure and mechanical properties of the aerogel can be controlled according to different requirements and applications [51]. The advantage of using 3D direct ink writing to print aerogel material is that they enable inks to be patterned in the filamentary form in the scope ranging from $100 \mu \mathrm{m}^{2}$ to $1 \mathrm{~m}^{2}$ with a minimum feature size of $1 \mu \mathrm{m}$ [16]. At the same time, 3D-printed 
graphene-based micro-lattices can exhibit excellent properties of high conductivity, light weight and super-compressibility [52].

Several studies on 3D printing energy storage devices have been reported. According to different printing materials, these studies can be classified into different categories, including CNT based material, graphene based material, LTO $\left(\mathrm{Li}_{4} \mathrm{Ti}_{5} \mathrm{O}_{12}\right)$ and LFP $\left(\mathrm{LiFePO}_{4}\right)$ based material, $\mathrm{LiMn}_{1-\mathrm{x}} \mathrm{Fe}_{x} \mathrm{PO}_{4}$ material and $\mathrm{Zn}$-based metallic oxides material. Because 3D direct ink writing is a new technique which be applied in the electrochemical energy storage device fabrication, in this review, we focus on the ink preparation, the printing process and electrochemical performance of devices in order to obtain a better understanding of 3D direct ink writing and develop a new concept for further material design.

\section{Carbon nanotube-based Materials for Electrodes Energy Storage Devices}

\subsection{D direct ink writing single-wall CNT Li-S battery}

Carbon nanotube (CNT) is a good candidate for microelectronic device applications due to its long mean-free path for acoustic phonon scattering, great carrier mobility, and its micro size.[53] Furthermore, Li-S battery is more likely to become the next generation of energy storage device since sulfur has a high theoretical capacity of $1675 \mathrm{mAh} \mathrm{g}^{-1}$. Recently, Craig et al. illustrated that single-walled carbon nanotubes infused with sulfur (S@SWNT) could be used as a well printable ink to fabricate Li-S battery by using the direct ink writing. For the ink design, sulfur was infused within the single-walled carbon nanotubes with $95 \%$ metallic character (SWNT-met) to prepare S@SWNT, which played the roles of integrated current collector and active material. The printing inks were prepared by dispersing SWNT-met and S@SWNT in the

cyclohexylpyrrolidone (CHP) carrier solvent at a concentration of $0.2 \mathrm{mg} \mathrm{mL}^{-1}$ with an ultrasonic 
treatment for 6-8 $\mathrm{h}$. CHP was a better carrier solvent than N-methylpyrrolidone (NMP) for Li-S battery, because NMP could cause CNT bundling inside the inks and the shape conformality of electrode was worse than that of CHP. An aluminum foil substrate was taped directly to the printing stage and it was annealed on the hotplate at $150{ }^{\circ} \mathrm{C}$ for $10-15$ min in order to remove residual CHP carrier solvent after printing. The electrolyte was prepared by mixing dioxolane and dimethoxyethane at the volume ratio of $1: 1$ and $1 \mathrm{M} \mathrm{LiCF}_{3} \mathrm{SO}_{3}$. The ink was printed on an aluminum foil and the linear borders and nearly perfect shape conformity of the ink squares indicated that the inks had an excellent printability. SEM images of electrodes revealed that a tightly interspersed SWNT network was formed after printing [54].

The electrochemical performance of the printed-electrodes showed the S@SWNT had a characteristic of pseudocapacitive electroactivity. Initially, the cathodic sweep had small peaks at $2.37 \mathrm{~V}, 2.05 \mathrm{~V}$ and $2.00 \mathrm{~V}\left(\mathrm{~V}\right.$ vs. $\left.\mathrm{Li} / \mathrm{Li}^{+}\right)$. During the subsequent sweeps, the latter two cathodic peaks became broader and shifted to $2.08 \mathrm{~V}$ and $1.91 \mathrm{~V}$. For the anodic side, there were two distinct peaks at $2.38 \mathrm{~V}$ and $2.43 \mathrm{~V}$ originally, and the magnitude of these two peaks diminished during the subsequent sweeps. The cycle performance of the printed S@SWNT under two different sizes of electrodes demonstrated that the $5 \times 5 \mathrm{~mm}$ electrode had a higher initial discharge capacity than the $2 \times 2 \mathrm{~mm}$, and it retained $\sim 96 \%$ of initial capacity after 100 cycles. Some explanations could be concluded regarding the different performances between two different sizes of electrodes including the arrangement and the size of SWNT interstices, interSWNT connectivity and pore spaces of electrode, etc. [54]. In general, the printed-S@SWNT electrodes would produce a stable discharge capacity in the range $700-800 \mathrm{mAh} \mathrm{g}^{-1} \mathrm{~S}$ which was larger than that of traditional 2D graphene/single-walled carbon nanotube (G/SWCNT) Li-S batteries with a capacity of $650 \mathrm{mAh} \mathrm{g}^{-1}$ after 100 cycles [55] . 


\subsection{D direct ink writing multi-wall CNT Li-S battery}

In order to discover a new pathway of 3D printed- Li-S battery via CNT material, Craig et al. also reported the Li-S battery fabrication by using multiwall carbon nanotubes (MWCNT). MWCNT-based electrodes are highly conductive and ultraporous, which are important for electronic, ionic and electrolyte transport inside the battery [56]. In this work [56], Craig et al. used MWCNT to print micro-electrodes which could provide high areal capacity of $7 \mathrm{~mA} \mathrm{~h} \mathrm{~cm}{ }^{-2}$ at $11.5 \mathrm{~mA} \mathrm{~cm}{ }^{-2}$ with the active material loading of $50 \mathrm{wt} \%$. Fig. 2(a) contains the process flow schematic outlining the 3D-printed electrodes fabrication. Basically, the MWCNT printing inks included aligned multiwall carbon nanotubes, DI water and isopropyl alcohol for the purpose of improving MWCNT wetting. The inks were dispersed by an ultrasonic treatment for $90 \mathrm{~min}$. The freestanding MWCNT microelectrodes were printed by using the fluid dispenser through a glass reservoir assembly which consisted of glass tubes and flanged bases. The structure of fluid dispenser is shown in the Fig. 2(a). After filtration, the MWCNT electrodes were rinsed with DI water, ethanol, acetone and dried in the vacuum oven. The electrolyte was prepared by dissolving lithium trifluoromethanesulfonate $\left(\mathrm{LiCF}_{3} \mathrm{SO}_{3}\right)$ and lithium nitrate $\left(\mathrm{LiNO}_{3}\right)$ in the mixture of dimethoxyethane and 1,3-dioxolane at the volume ratio of 1:1 in order to prepare $1 \mathrm{M}$ $\mathrm{LiCF}_{3} \mathrm{SO}_{3}$ and $0.1 \mathrm{M} \mathrm{LiNO}_{3}$ solutions. Stoichiometric amounts of sublimed sulfur powder and lithium sulfide $\left(\mathrm{Li}_{2} \mathrm{~S}\right)$ were added to the electrolyte to generate polysulfide catholyte solutions $\left(\mathrm{Li}_{2} \mathrm{~S}_{6}\right)[57]$.

The electrochemical performance is presented in Fig. 2(b-c). Fig. 2(b) shows the voltage profiles as a function of cycle number for the cell with $3.4 \mathrm{mg}$ sulfur $\mathrm{cm}^{-2}$ at $\mathrm{C} / 2$ rate. During the initial charge, the figure only showed the sloping region and the upper plateau, which indicated 
that the polysulfides were dissolved in the initial charge. After several cycles, the upper plateau of voltage profiles extended from 2.4 to $2.35 \mathrm{~V}$ and the lower plateau was stable at $2.05 \mathrm{~V}$. Fig. 2(c) demonstrates the galvanostatic cycling performances for different sulfur loadings of 3.4 and $6.8 \mathrm{mg} \mathrm{S} \mathrm{cm}^{-2}$ at cycle rate of $\mathrm{C} / 2$ and $1 \mathrm{C}$. The specific discharge capacities tended to be constant after 25 cycles for both of sulfur loadings. As shown in the figure, the discharge capacities for high loading electrodes were above $735.3 \mathrm{~mA} \mathrm{~h} \mathrm{~g}^{-1}$ for the first 50 cycles at rate of $\mathrm{C} / 2$ and $1 \mathrm{C}$. After 200 cycles, the discharge capacity was stable at $514.7 \mathrm{~mA} \mathrm{~h} \mathrm{~g}^{-1}$ for high sulfur loading at $\mathrm{C} / 2$ and $1 \mathrm{C}$ rate. And the discharge capacity was $735.3 \mathrm{~mA} \mathrm{~h} \mathrm{~g}^{-1}$ for low sulfur loading at $\mathrm{C} / 2$ rate, $588.2 \mathrm{~mA} \mathrm{~h} \mathrm{~g}^{-1}$ at $1 \mathrm{C}$ rate. These results met the benchmark of the microelectrode performance which was 5-10 $\mathrm{mA} \mathrm{h} \mathrm{cm}^{-2}$ for microelectronic devices [20]. Furthermore, it was a big improvement of capacity compared with the traditional carbon nanofiber-sulfur composite Li-S battery with a rate capability of $437 \mathrm{~mA} \mathrm{~h} \mathrm{~g}^{-1}$ at $1 \mathrm{~A} \mathrm{~g}^{-1}[58]$.
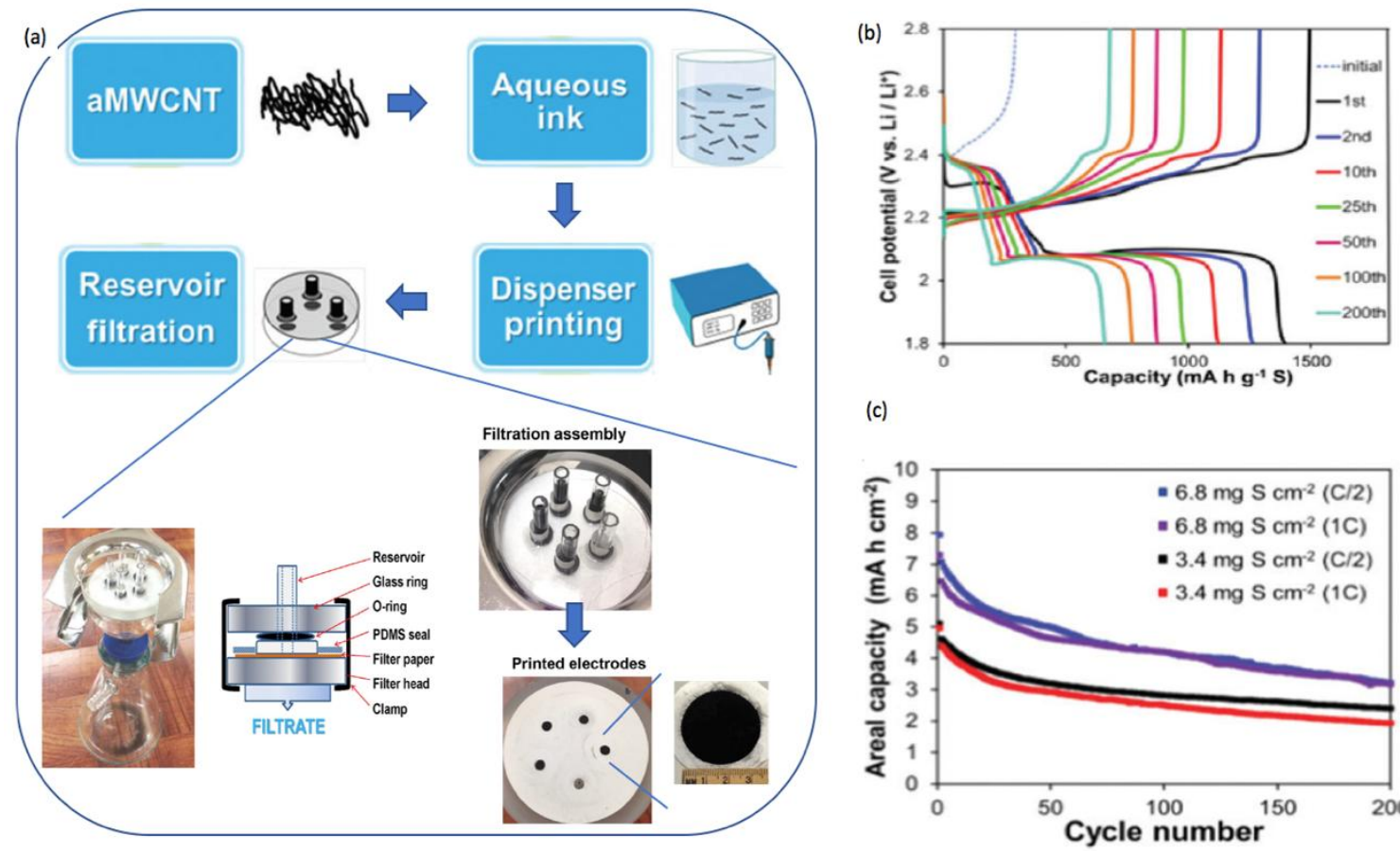

(c)

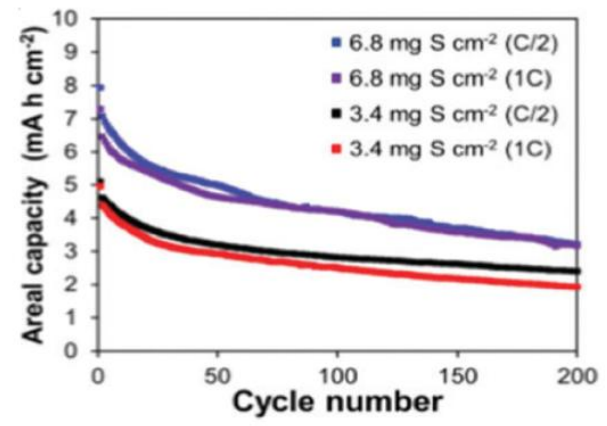


Fig. 2. (a) Schematic illustration of the fabrication process, (b) Voltage profiles during galvanostatic discharge cycling as a function of cycle number, (c) Cycle performance for cell with 3.4 and $6.8 \mathrm{mg} \mathrm{cm}^{-2}$ sulfur loadings cycled at $\mathrm{C} / 2$ and $1 \mathrm{C}$ rates. With reprint permission from Ref [57].

\section{Graphene-based Materials for Energy Storage Devices}

\subsection{D direct ink writing graphene aerogel supercapacitor}

One of the big challenges of direct-ink writing is to design gel-based viscoelastic ink materials with non-Newtonian shear thinning behavior, for the purpose of facilitating flow under a fast pseudo-plastic to dilatant recovery and enhancing the shape retention [52]. According to the results presented by Cheng et al., by adding different functional fillers, such as silica filler, conductive nanoparticles, or nanofibers, the physical and electrochemical properties of the inks were improved $[59,60]$. Thus, it is important to prepare printable graphene oxide (GO) inks with high viscosity and self-supporting shape integrity after the deposition for 3D printing graphene aerogel supercapacitor [52].

Fig. 3(a) demonstrates the apparent viscosity of GO suspension as a function of shear rate. GO suspensions were prepared by ultrasonic treatment of 20 and $40 \mathrm{mg} \mathrm{ml}^{-1} \mathrm{GO}$ in DI water for $24 \mathrm{~h}$. With increasing the GO suspension concentration, the suspension exhibited higher apparent viscosity, higher shear rate and better printability [61]. Note that a higher weight percentage of silica filler with a submicron particle size was added in the GO suspension to increase the viscosity [62]. Thus, the printability of the GO inks could be enhanced during the printing process [52]. Fig. 3(b) shows the relationship between moduli and shear stress for GO suspensions with and without silica filler. Based on this figure, $20 \mathrm{mg} \mathrm{ml}^{-1} \mathrm{GO}$ suspensions 
without silica filler had an elastic modulus value of about 1,000 Pa and a yield stress of about 40 $\mathrm{Pa}$ [52]. It was clearly seen that the elastic modulus and yield stress of $40 \mathrm{mg} \mathrm{ml}^{-1} \mathrm{GO}$ suspensions with silica filler increased by over one order of magnitude. As a consequence, the GO suspensions of higher concentration with higher amount of silica filler could improve the printability of the inks.

The process of 3D printing graphene aerogel supercapacitor is illustrated in Fig. 3(c). To achieve the ideal printable ink, Cheng et al. prepared ink by adding $3.6 \mathrm{~g}$ high concentration GO suspensions $\left(40 \mathrm{mg} \mathrm{ml}^{-1}\right)$ and $0.9 \mathrm{~g}$ silica filler. Eventually, $0.3 \mathrm{~g}$ graphene nanoplatelets (GNPs) were added along with the $2.0 \mathrm{~g}$ resorcinol-formaldehyde (R-F) solution to induce gelation by introducing chemical bonding between GO sheets [63]. The aerogel microstructure could be improved by the gelation method as was shown in some previous studies [63]. As the 3D-printed pure graphene aerogels alone without graphene nanoplatelets and organic solvents were not ideal material due to the high electrical resistance for supercapacitor, graphene nanoplatelets were added in the GO suspensions in order to increase the electrical conductivity and lower the resistance. In this way, homogenous, thixotropic and highly viscous inks were prepared. In order to successfully convert the 3D printed GO structure to an aerogel, it was important to keep the GO inks wet during the printing and gelation process. The printed structures could then be processed into aerogels by following the steps of gelation, freeze-drying or supercritical-drying, and etching of the silica with hydrofluoric acid $[64,65]$. The liquid in the pores of the wet gel could be removed by using freeze-drying or supercritical-drying to avoid gel collapse due to capillary forces [52]. This printing work was carried out in an organic solvent (2,2,4-trimethylpentane) which was less dense than water and was immiscible with the GO inks [66]. The structure of the 3D-printed graphene was designed as simple cubic lattices which consisted of 
multiple orthogonal layers of parallel cylindrical filaments printed in a layer-by-layer structure with a pore volume of $0.25 \mathrm{~cm}^{3}$. These results illustrated that the aerogel which was fabricated by 3D direct ink writing exhibited a great structural integrity, micro-architecture accuracy and good quality of printing [52].

(a)

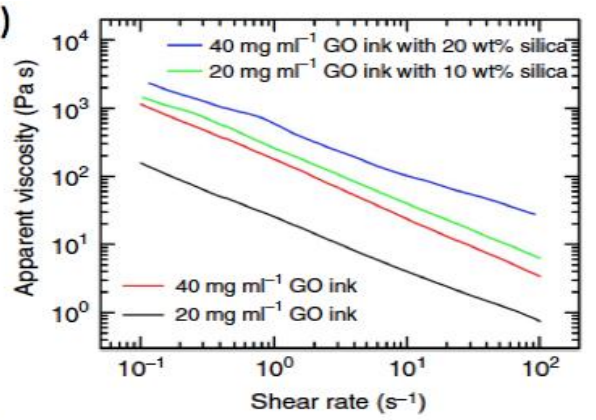

(c)

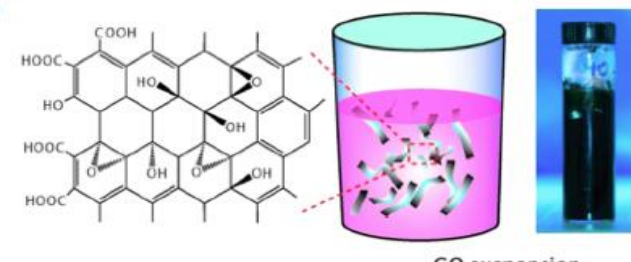

GO suspension
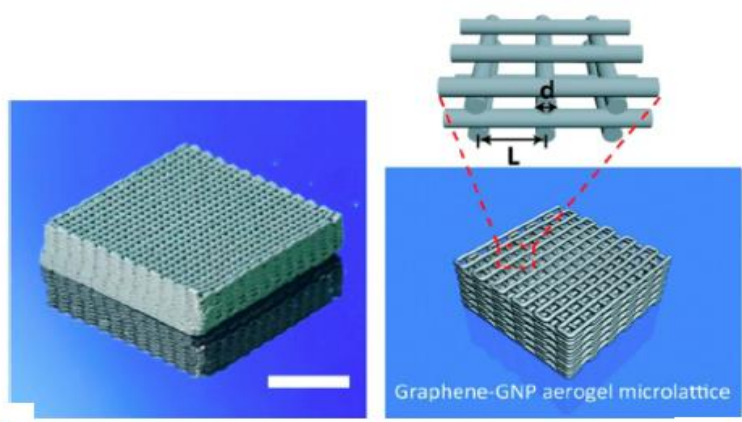

(d)

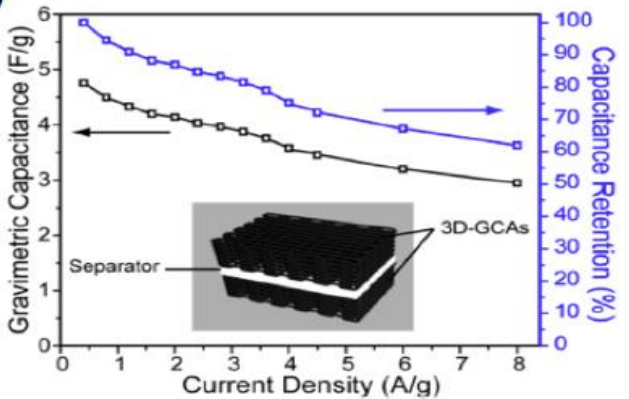

(b)
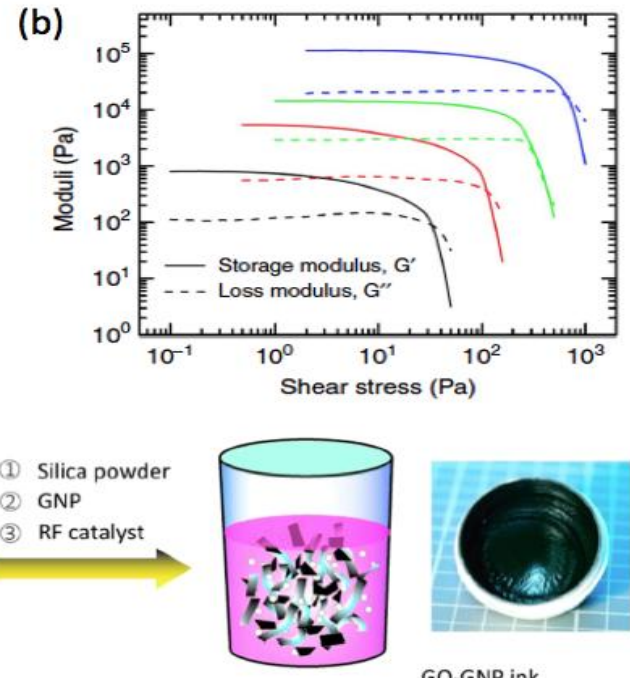

GO-GNP ink $3 \mathrm{D}$ printing

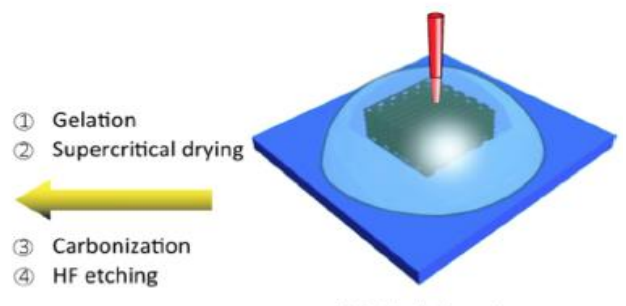

Printing in isooctane (e)

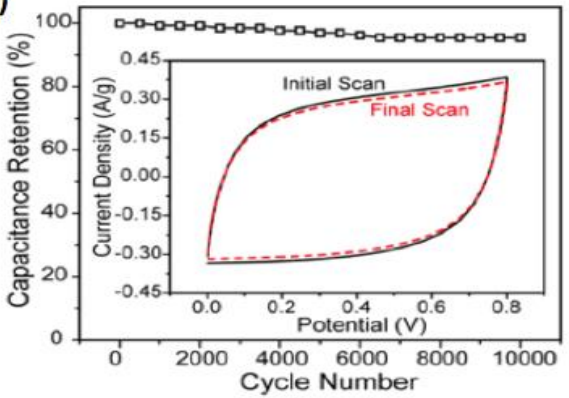


Fig. 3. (a) Log-log plots of apparent viscosity as a function of shear rate of GO suspension (20 $\mathrm{mg} \mathrm{ml}^{-1}$ and $40 \mathrm{mg} \mathrm{ml}^{-1}$ ), (b) Log-log plots of storage and loss modulus as a function of shear stress of GO suspension (20 mg ml $\mathrm{mg}^{-1}$ and $40 \mathrm{mg} \mathrm{ml}^{-1}$ ) with and without silica fillers, (c) Schematic illustration of the fabrication process, (d) Gravimetric capacitance and capacitive retention calculated as a function of current density, (e) Cycling stability test for 10,000 cycles. With reprint permission from Ref $[39,52]$.

The electrochemical performance, e.g., cyclic voltammetry (CV), chronopotentiometry, gravimetric capacitance and cycling stability, of 3D-printed graphene composite aerogel (3DGCA) electrodes was evaluated in an aqueous electrolyte of $3 \mathrm{M} \mathrm{KOH}$ in DI water [39]. The results are illustrated in the Fig. 3(d-e). All 3D GCA symmetric supercapacitor (SSC) samples demonstrated $\mathrm{CV}$ curves with quasi-rectangular shape at different scan rate and a triangular shape of charge and discharge profiles, which indicated that the 3D GCA SSC exhibited nearideal electrical double layer capacitive behavior with small internal resistance [67-69]. The maximum gravimetric capacitance of the 3D-GCA SSC was $4.76 \mathrm{~F} \mathrm{~g}^{-1}$ at a current density of 0.4 $\mathrm{A} \mathrm{g}^{-1}$, and $61 \%$ of the maximum gravimetric capacitance remained when the current density was increased to $8 \mathrm{~A} \mathrm{~g}^{-1}$ [39]. Compared to other carbon-based symmetric supercapacitors (SSCs), the gravimetric capacitance for CNT-coated paper-based SSC was $0.38 \mathrm{~F} \mathrm{~g}^{-1}$ [70] and the activated carbon cloth-based SSC was $0.765 \mathrm{mF} \mathrm{g}^{-1}$ [67]. Nevertheless, the 3D-GCA SSC achieved much higher gravimetric capacitance and exhibited great electrochemical stability with a capacitance retention of $95.5 \%$ after 10,000 consecutive charge and discharge cycles at a scan rate of $200 \mathrm{mV} \mathrm{s}^{-1}$. 


\subsection{D direct ink writing graphene hydrogel (GH)- polyaniline (PANI) supercapacitor}

Besides the graphene aerogel, graphene hydrogel is the other material that be used in 3D direct ink writing for preparing supercapacitors. Over the past few years, freestanding graphenebased paper-like structure (GP) has attracted considerable interest in flexible supercapacitor because of its high electrical conductivity of $10^{3}-10^{4} \mathrm{~S} \mathrm{~m}^{-1}$ and large surface area of $2630 \mathrm{~m}^{2} \mathrm{~g}^{-1}$ [71]. Compared with traditional fabrication methods, such as vacuum filtering and self-assembly, 3D direct ink writing technique provides an advanced method to fabricate GP and devices with large-area and low cost [72]. Additionally, the thickness of GP and the shape or dimension can be controlled by the 3D direct ink writing. Recently, Kai et al. reported a new type of nanohybrid paper electrode based on 3D direct ink printing technique for supercapacitor applications. As Fig. 4(a) demonstrates in this work, a 3D graphene hydrogel loaded polyaniline (GH-PANI) ink was prepared by ball milling and ultrasonic treatment of GH-PANI nanomaterial in DI water. Graphene oxide (GO) ink was printed on a commercial paper first by the direct ink writing technique and 3D GH would self-assemble from GO through $\pi$ - $\pi$ stacking. GH-PANI ink was then overprinted on the GO paper (GOP). After hydroiodic acid (HI) reduction reaction, the freestanding GH-PANI/GP was peeled off from the commercial paper substrate [73]. Moreover, a gel electrolyte was prepared by mixing $\mathrm{H}_{2} \mathrm{SO}_{4}$, poly (vinyl alcohol) (PVA) and DI water under $85{ }^{\circ} \mathrm{C}$ for $1 \mathrm{~h}$. The supercapacitor was finally assembled by combining of electrodes $(\mathrm{GH}-$ PANI/GP), electrolyte and a cellulose separator. Fig. 4(b) shows the differences between different graphene-based inks and their paper material; the flexibility was greatly improved for GH-PANI/GP.

The electrochemical performance is shown in the Fig. 4(c-e). The supercapacitor prepared by the direct ink writing exhibited remarkable mechanical flexibility. As shown in the 
figures, the operating voltage was set at $0.8 \mathrm{~V}$ during the experiment, and the energy density of the supercapacitor was $24.02 \mathrm{Wh} \mathrm{kg}^{-1}$ at a power density of $400.33 \mathrm{~W} \mathrm{~kg}^{-1}$. In addition, the supercapacitor also showed a good long-term cycling stability; it retained $85.6 \%$ of the initial capacitance after 5,000 cycles at a fixed current density of $8 \mathrm{~A} \mathrm{~g}^{-1}$ [73].
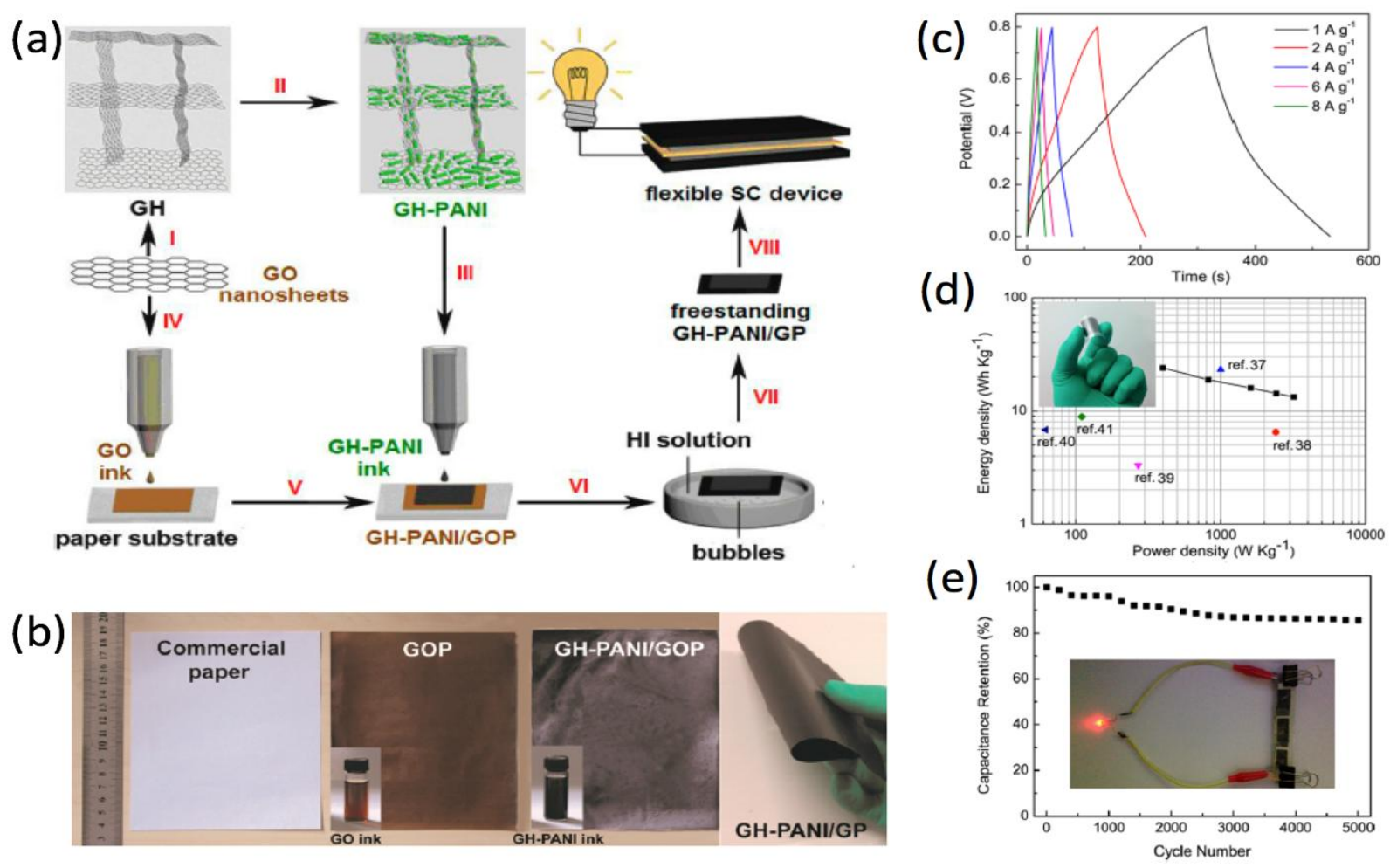

Fig. 4. (a) Schematic illustration of GH-PANI/GP supercapacitor, (b) Photographs of different graphene-based inks and nanohybrid paper materials, (c) GA charge-discharge curves of supercapacitor, (d) Power density and energy density of supercapacitor compared with other literatures, (e) Cycling Behavior of Supercapacitor at a current density of $8 \mathrm{~A} \mathrm{~g}^{-1}$. With reprint permission from Ref [73]. 


\section{LTO and LFP-based Materials for Energy Storage Devices}

\subsection{D direct ink writing LTO and LFP Li-ion micro-battery}

A rapidly developing market for microscale devices, such as actuator drives [74], biomedical sensors [75] and micro-electro-mechanical systems (MEMS) [76] has attracted attention from academia. Scientists try to fabricate micro-battery as 3D structure because it can double the energy density by fully using the limited space [77]. As 3D direct ink writing techniques develop, they provide a precise method to fabricate 3D interdigitated micro-battery architectures (3D-IMA). Recently, a 3D-IMA was designed by Ke et al., where LTO $\left(\mathrm{Li}_{4} \mathrm{Ti}_{5} \mathrm{O}_{12}\right)$ and LFP $\left(\mathrm{LiFePO}_{4}\right)$ have been employed as the anode and cathode materials in the Li-ion microbattery. These materials exhibited minimal volumetric expansion, which could better accommodate strain in the electrode during the charge and discharge processes [16].

Optimized concentrated cathode and anode inks are important to fabricate 3D-IMA. Concentrated anode and cathode inks were prepared by suspending nanoparticles of LTO with a mean diameter of $50 \mathrm{~nm}$ and LFP with a particle size of less than $300 \mathrm{~nm}$ in a solution consisting of DI water, ethylene glycol, glycerol and cellulose-based viscosifiers. After several trials, the inks with the desired rheological and printing behavior consisted of LTO with the $57 \mathrm{wt} \%$ solids loading and LFP with $60 \mathrm{wt} \%$ solids loading. Under these conditions, both LTO and LFP inks have viscosities ranging from $10^{3}$ to $10^{4} \mathrm{~Pa} \cdot \mathrm{s}$ at $1 \mathrm{~s}^{-1}$, the plateau modulus is near $10^{6} \mathrm{~Pa}$ and their shear yield stress in the range $10^{2}$ to $10^{3} \mathrm{~Pa}$. Images of LTO and LFP ink are presented in Fig. 5(a). LTO and LFP ink were exactly printed by following the pattern of the current collector. The process is presented in Fig. 5(b) [16]. A graded volatile solvent system which included deionized water, ethylene glycol and glycerol was used to control the ink adhesion and solidification during the $3 \mathrm{D}$ printing process. DI water evaporated first during the printing due to 
its low boiling point $\left(100{ }^{\circ} \mathrm{C}\right)$, which helped to induce partial solidification of the printed features. Ethylene glycol and glycerol acted as humectants to reinforce the bonding between each layer [78]. After the printing was finished, the LTO and LFP microelectrode arrays were heated to $600{ }^{\circ} \mathrm{C}$ in inert gas to remove the organic solvent and speed up the nanoparticle sintering [16]. From Fig. 5(c), the microstructure of electrodes indicated that the 3D structure could remain highly porous and convenient for electrolyte penetration [79].

Fig. 5(d) depicts a 3D-IMA composed of LTO-LFP electrodes after packaging. The small plastic case contained the Li-ion micro-battery and liquid electrolyte. The liquid electrolyte was prepared by mixing $1 \mathrm{M} \mathrm{LiClO}_{4}$ at 1:1 volume ratio of ethylene carbonate and dimethyl carbonate [16]. Fig. 5(e) shows the cyclic voltammetry (CV) test at a constant scan rate of $5 \mathrm{mV} \mathrm{s}^{-1}$ between voltage of 1.0 and $2.5 \mathrm{~V}$. It became apparent that the stable reduction peak occurred at $1.3 \mathrm{~V}$ and the stable oxidation peak occurred at $2.4 \mathrm{~V}$. Furthermore, Fig. 5(f) shows the galvanostatic charge and discharge profile of the packaged 3D-IMA at a rate of $0.5 \mathrm{C}$, a capacity of about $1.2 \mathrm{mAh} \mathrm{cm}^{-2}$ with a low potential gap between charge and discharge [16]. Notably, the 3D-IMA fabricated in this work [16] could perform a high areal energy density of $9.7 \mathrm{~J} \mathrm{~cm}^{-2}$ at a power density of $2.7 \mathrm{~mW} \mathrm{~cm} \mathrm{c}^{-2}$. However, 3D-IMA showed a low coulombic efficiency for each cycle and poor long-term cyclability due to the hermeticity of the device, which suggested that a further optimization of 3D-IMA should be considered. 

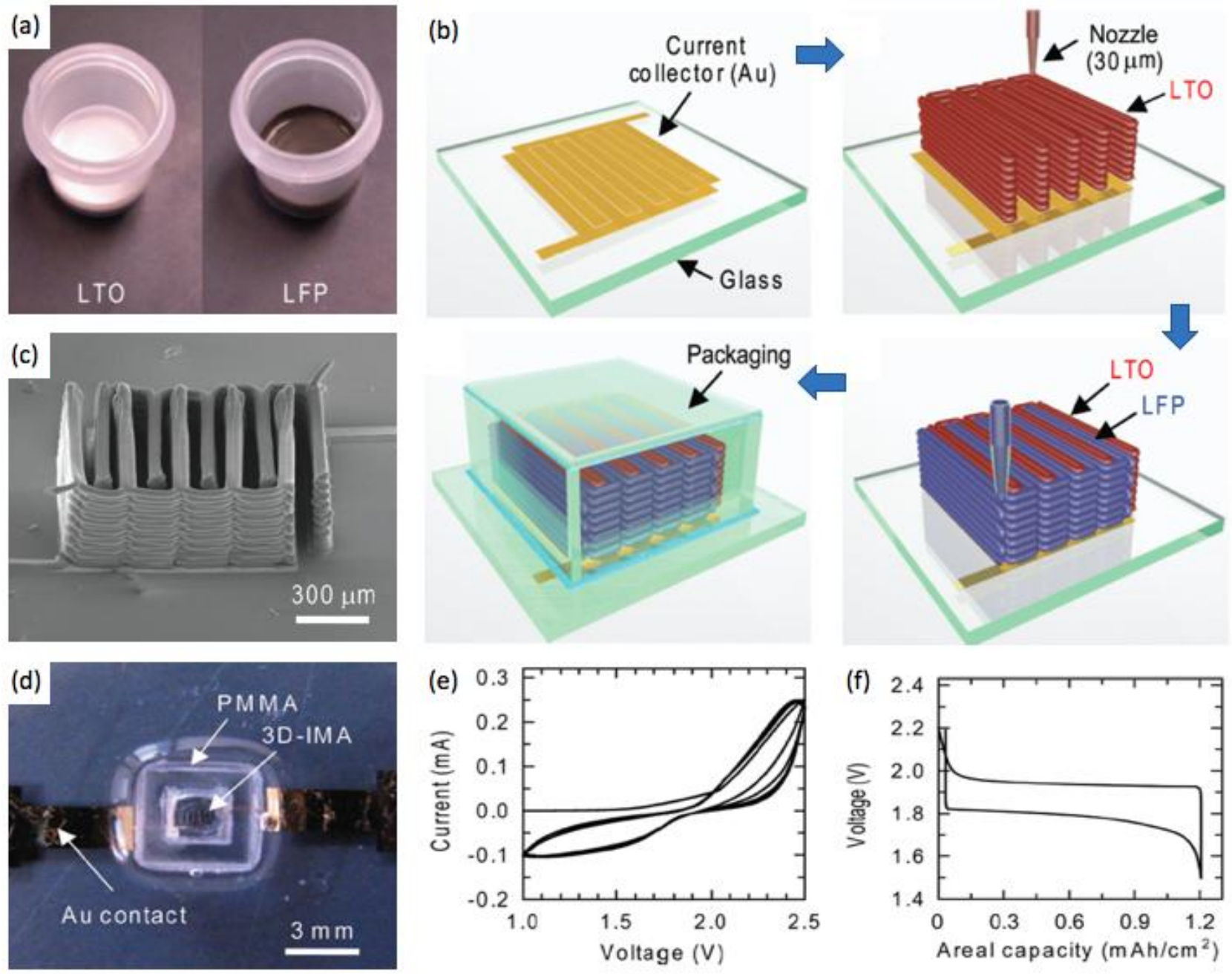

Fig. 5. (a) Images of LTO and LFP inks, (b) Schematic illustration of Li-ion battery, (c) SEM image of printed LTO-LFP electrode architecture, (d) 3D-IMA composed of LTO-LFP 
electrodes after packaging, (e) Cyclic voltammetry of 3D-IMA, (f) Charge and discharge curve of 3D-IMA. With reprint permission from Ref [16].

\subsection{D direct ink writing LTO/GO, LFP/GO Li-ion battery}

In order to improve the electrical conductivity of electrodes, graphene oxide (GO) is added into the inks, not only because it is a good candidate to provide high electrical conductivity to fabricate 3D printed electrodes, but also because of its noteworthy printing capabilities and distinctive viscoelastic properties [80]. Kun et al. developed LTO/GO, LFP/GO electrode inks for Li-ion battery by using 3D direct ink writing. As mentioned in Section 1, the inks with high concentration of GO exhibited gel-like property with a high elastic modulus. Instead, the low concentration of GO inks showed liquid-like property, which was improper for 3D direct ink writing [81]. Fig. 6(a) shows a schematic of the 3D-printed lithium-ion battery by using LTO/GO, LFP/GO inks. In this work [37], LFP and LTO were selected as electrode active

material, and the highly concentrated aqueous GO-based inks ( $80 \mathrm{mg} \mathrm{ml}^{-1}$ ) composed of GO sheets with an average thickness of $2.5 \mathrm{~nm}$ and electrode active material. DI water worked as solvent to make inks feasible for printing since it is inexpensive and safe during the drying process. GO sheets had a high surface area, and the electrode active materials can be loaded on their surface. Briefly, GO sheets and electrode active material were uniformly mixed together, the cathode and anode inks were then prepared separately and stored in two syringes. As shown in Fig. 6(a), filaments of good fluidity were extruded directly from a nozzle and deposited layerby-layer using the computerized printing routine. The GO flakes were aligned along the printing direction because GO sheets exhibited an anisotropic liquid crystalline behavior in the aqueous solution. After the architectures of both electrodes were printed, freeze-drying was employed to 
remove the water and solidify the $3 \mathrm{D}$ structure of the device. During the drying process, due to the strong H-bonding between the water molecules and the functional groups on the surface of GO, the fresh electrodes would be shelved for more than ten hours without any structural damage. [37] After freeze drying, a thermal annealing process $\left(600{ }^{\circ} \mathrm{C}\right.$ in $\mathrm{Ar} / \mathrm{H}_{2}$ for $\left.2 \mathrm{~h}\right)$ was applied to reduce the $\mathrm{GO}$ in the $3 \mathrm{D}$ structure to graphene [82]. Furthermore, GO with the porous structure would also offer a large space to accommodate the gel electrolyte. From Fig. 6(a), the channels between two interdigitated annealed electrodes were printed with a polymer composite ink consisting of poly(vinylidenefluoride)-co-hexafluoropropylene (PVDF-co-HFP) and $\mathrm{Al}_{2} \mathrm{O}_{3}$ at a mass ratio of 1:10 in N-Methyl-2-Pyrrolidone (NMP) solvent, which served as gel polymer electrolyte and electrically insulated separator [37].
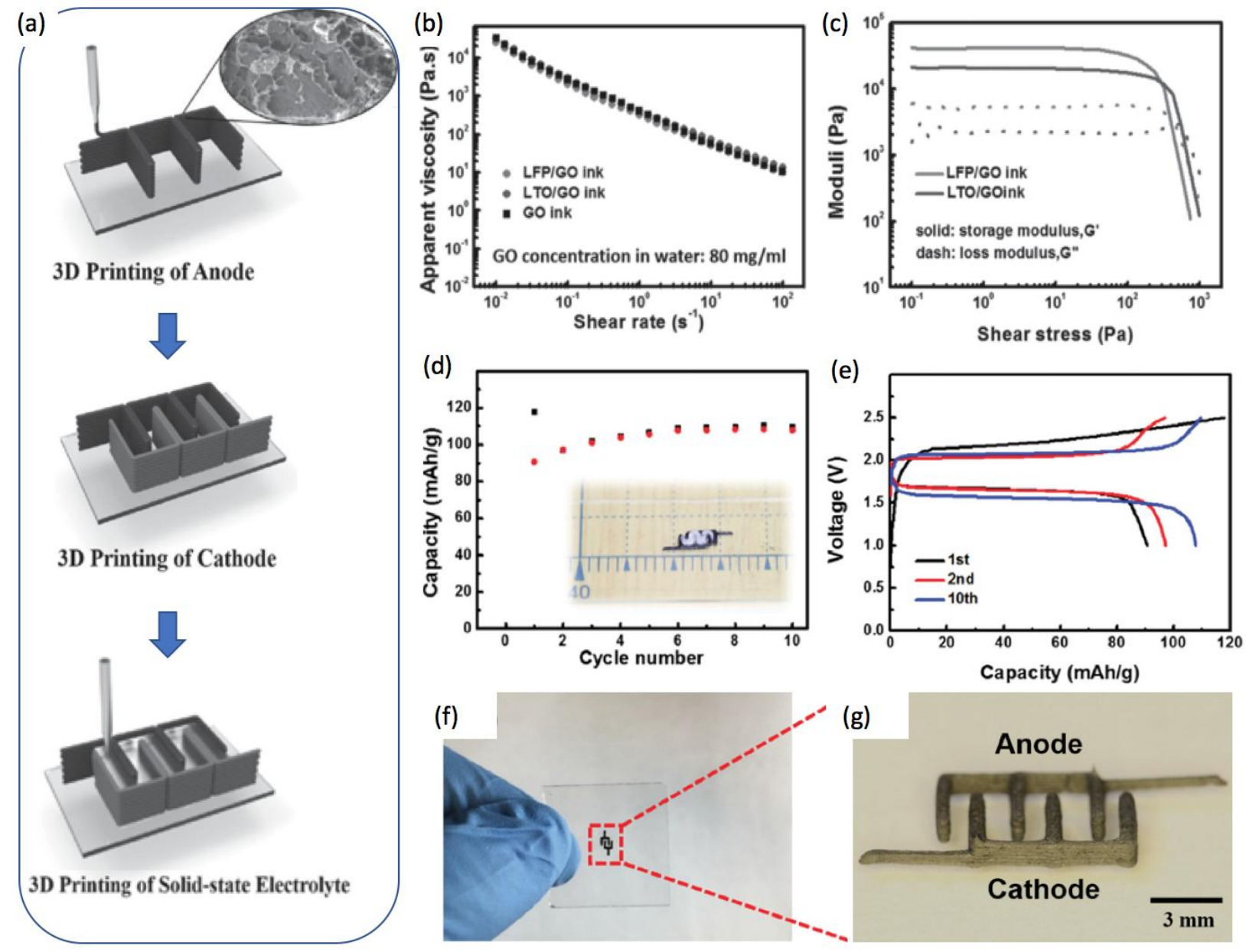
Fig. 6. (a) Schematic illustration of 3D-printed interdigitated electrodes, (b) Apparent viscosity as a function of shear rate for GO, LFP/GO, LTO/GO inks, (c) Storage modulus, G, and loss modulus, G' as a function of shear stress for LFP/GO, LTO/GO inks, (d) Cycling stability of the battery, (e) Charge and discharge profiles of the battery, (f, g) Image of the 3D-printed electrodes. With reprint permission from Ref [37].

The physical properties are shown in Fig. 6(b-c). Fig. 6(b) displays the relationship between apparent viscosity and shear rate for inks containing only GO, LFP/GO, and LTO/GO respectively. The concentration of GO was $85 \mathrm{mg} \mathrm{mL}^{-1}$. The mass ratio of LFP or LTO to GO was kept at 7:3 with a GO concentration of $80 \mathrm{mg} \mathrm{mL}^{-1}$ in DI water. From the figure, the three types of inks showed a similar viscosity curve with an apparent viscosity ranging from $10^{2}$ to $10^{3}$ $\mathrm{Pa}$ at a shear rate of $1 \mathrm{~s}^{-1}$, which indicated that GO dominates the viscosity behavior of the inks. LFP and LTO nanoparticles did not have significant influence to the rheological properties of inks even when a large amount of electrode active materials was added. The relationship between elastic moduli/viscous moduli of LFP/GO and LTO/GO inks and shear stress is presented in Fig. 6(c). The storage modulus values were $10^{4}$ to $10^{5}$ for both inks during plateau region, and a high yield stress of $10^{3} \mathrm{~Pa}$. As a result, large values of storage modulus and yield stress for 3D direct ink writing were achieved. Additionally, the values of elastic and viscous modulus of inks did not change much over time, indicating that the rheological stability was excellent during the drying process. A polymer composite ink with a low viscosity could easily be printed in the channels between two electrodes and made a good contact with them [37]. 
The electrochemical performance of Li-ion battery which consists of 3D-printed interdigitated electrodes and polymer electrolyte is shown in Fig. 6(d-e). In their work [37], Kun et al. tested both half cells and full cell. During the half cells test, a liquid electrolyte was prepared by using $1 \mathrm{M} \mathrm{LiPF}_{6}$ in ethylene carbonate and diethyl carbonate. The conditions of the test were set at a voltage range of $2-4 \mathrm{~V}$ at a specific current of $10 \mathrm{~mA} \mathrm{~g}^{-1}$. The initial charge and discharge capacity of LFP/rGO were near $168 \mathrm{mAh} \mathrm{g}^{-1}$ and $164 \mathrm{mAh} \mathrm{g}^{-1}$. After the $10^{\text {th }}$ and $20^{\text {th }}$ cycles, the charge and discharge capacity of $170 \mathrm{mAh} \mathrm{g}^{-1}$ was maintained with a voltage hysteresis of about $0.1 \mathrm{~V}$. On the other hand, the electrode of LTO/rGO exhibited an initial charge and discharge capacities of $184 \mathrm{mAh} \mathrm{g}^{-1}$ and $185 \mathrm{mAh} \mathrm{g}^{-1}$ under a specific current of 10 $\mathrm{mA} \mathrm{g}^{-1}$. After increasing of cycle number, the capacity of LTO/rGO slightly decreased, but the voltage hysteresis almost remained the same. By increasing the specific currents of the LTO half-cell measurement, the discharge capacities changed from $171 \mathrm{mAh} \mathrm{g}^{-1}$ at $10 \mathrm{~mA} \mathrm{~g}^{-1}$ to 73 $\mathrm{mAh} \mathrm{g}^{-1}$ at $200 \mathrm{~mA} \mathrm{~g}^{-1}$. It should be noted that the capacity of LTO-based electrode decreased faster than that of LFP-based electrode. This was explained by the shorter $\mathrm{Li}^{+}$diffusion distance for smaller nanoparticle (LFP had a dimeter less than $50 \mathrm{~nm}$ ) that resulted in fast insertion kinetics of ions at increasing specific currents [37]. The test of the 3D-printed full cell was based on the loadings of $3.8 \mathrm{mg}$ cathode and $3.9 \mathrm{mg}$ anode under $50 \mathrm{~mA} \mathrm{~g}{ }^{-1}$. Fig. $6(\mathbf{d})$ demonstrates that the capacity of the full cell was about $100 \mathrm{mAh} \mathrm{g}^{-1}$ with the initial charge and discharge capacities were around $117 \mathrm{mAh} \mathrm{g}^{-1}$ and $91 \mathrm{mAh} \mathrm{g}^{-1}$. Moreover, as the cycle number increases, the discharge capacity increased to $108 \mathrm{mAh} \mathrm{g}^{-1}$ after $10^{\text {th }}$ cycle as shown in Fig. 6(e). This indicated that the activation of electrode was strengthened after several cycles. The full cell showed a good cycle stability with $92.3 \%$ of initial capacity remaining. The $2 \mathrm{D}$ structure LTOLFP battery only exhibited a specific capacity of about $60 \mathrm{~mA} \mathrm{~h} \mathrm{~g}{ }^{-1}$ after 300 cycles. Fig. 6(f) 
shows the image of the 3D-printed electrodes and the layer-by-layer structure was very clearly observed in Fig. 6(g) [37].

\section{5. $\mathrm{LiMn}_{1-\mathrm{x}} \mathrm{Fe}_{\mathrm{x}} \mathrm{PO}_{4}$ based Materials for Energy Storage Devices}

\subsection{D direct ink writing $\mathrm{LiMn}_{1-\mathrm{x}} \mathrm{Fe}_{\mathrm{x}} \mathrm{PO}_{4}(\mathrm{LMFP})$ based cathodes for Li-ion battery}

Recently, $\mathrm{Hu}$ et al. developed a 3D Li-ion battery based on $\mathrm{LiMn}_{0.21} \mathrm{Fe}_{0.79} \mathrm{PO}_{4}(\mathrm{LMFP})$ nanocrystal cathodes. LMFP could provide higher energy density with higher working voltage than pure $\mathrm{LiFePO}_{4}$ because $\mathrm{LiMnPO}_{4}$ has a higher redox potential of $4.1 \mathrm{~V}$ than $\mathrm{LiFePO}_{4}$ of 3.4 V [83]. Fig. 7(a) shows the schematic of 3D-printed LMFP based cathodes Li-ion battery. Step I describes a synthesis process for LMFP through calcination and carbon coating processes. Step II shows the printing process with the resulting slurry. In this work [84], the slurry consisted of the active materials (LMFP), XC-72 carbon black, poly(vinylidene fluoride) (PVDF) mixed in Nmethylpyrrolidine (NMP) at a weight ratio of 5:3:2. The slurry was pushed out of the micronozzle by pressure. The electrolyte was prepared by $1 \mathrm{M} \mathrm{LiFP}_{6}$ which was dissolved in a mixture of ethylene carbonate (EC), diethyl carbonate (DEC), and dimethyl carbonate at a volume ratio of 1:1:1. The Li-ion battery was assembled with lithium foil which served as the counter electrode and reference electrode, LMFP cathode, electrolyte and lithium. The device is presented in Fig. 7(a).

In order to demonstrate the advantages of 3D-printed electrodes, $\mathrm{Hu}$ et al. compared the electrochemical performance between 3D-printed electrode and the coating electrode which were prepared by using same materials. Fig. 7(b-c) shows the charge-discharge voltage curves of 3Dprinted electrode and the coating electrode at different rates from $1 \mathrm{C}$ to $100 \mathrm{C}$. The discharge capacity of the 3D-printed electrode was from 161.36 to $108.45 \mathrm{mAh} \mathrm{g}^{-1}$ at the rates of $1 \mathrm{C}$ to 
$100 \mathrm{C}$, much better than the coating electrode which had the discharge capacity from 141 to 70 $\mathrm{mAh} \mathrm{g}^{-1}$. Fig. 7(d-e) indicates that under different current rates, the specific capacity of 3Dprinted electrode was always better than of the coating electrodes. After 1000 cycles, the specific capacities of 3D-printed electrode were $150.21 \mathrm{mAh} \mathrm{g}^{-1}$ at $10 \mathrm{C}$ and $140.67 \mathrm{mAh} \mathrm{g}^{-1}$ at $20 \mathrm{C}$. By contrast, the specific capacities of the coating electrode were only $103.38 \mathrm{mAh} \mathrm{g}^{-1}$ at $10 \mathrm{C}$ and $90.64 \mathrm{mAh} \mathrm{g}^{-1}$ at $20 \mathrm{C}$. Therefore, 3D-printed electrode Li-ion battery exhibited a better longterm stability than the coating electrode Li-ion battery, and it achieved a high charging/discharging rate and high capacity [38, 84].
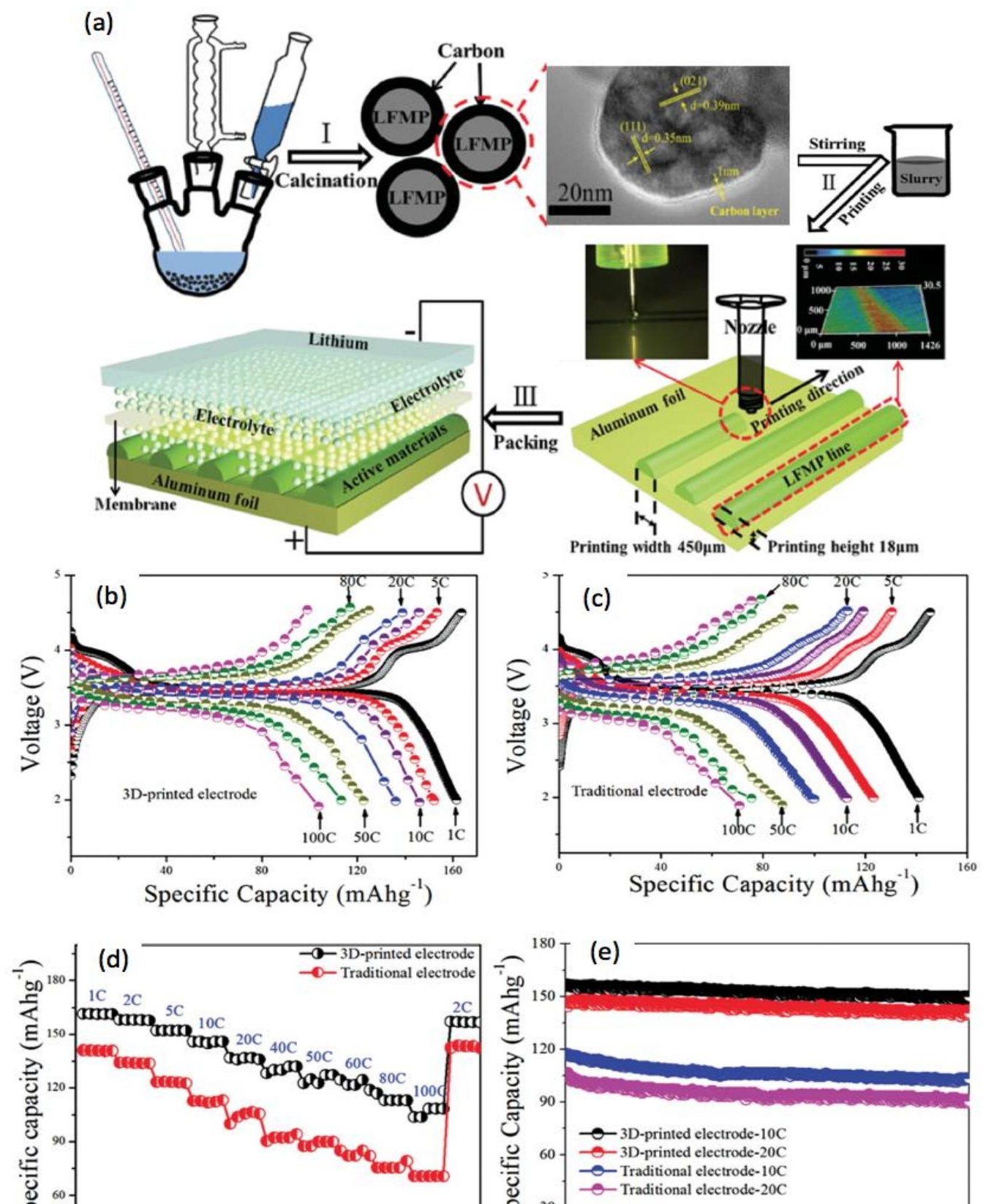
Fig. 7. (a) Schematic illustration of 3D-printed LMFP based cathodes Li-ion battery; Step I shows synthesis process for LMFP; Step II shows the printing process for electrodes; Step III is the packing process. (b) Charge-discharge voltage curves of 3D-printed electrodes at different rates, (c) Charge-discharge voltage curves of traditional electrodes at different rates, (d) Rate performance contrast between 3D-printed electrodes and traditional electrodes, (e) Cycling stability of 3D-printed Li-ion battery and traditional battery for 1,000 cycles. With reprint permission from Ref [84].

\section{Metal (Zn)- based Materials for Energy Storage Devices}

\subsection{D direct ink writing zinc-silver micro-battery}

In comparison to commercial Li-ion batteries, which can provide a specific energy of 150 Wh $\mathrm{kg}^{-1}$, zinc-silver batteries can offer high specific energy up to $300 \mathrm{Wh} \mathrm{kg}^{-1}$, and high power density of $600 \mathrm{~W} \mathrm{~kg}^{-1}$ [85]. Moreover, the materials which are applied in zinc-silver batteries are less dangerous and less-flammable than Li-ion batteries [32]. Several 3D micro-battery architectures have been demonstrated by the direct ink writing with a minimum feature size of 15 $\mu \mathrm{m}$. Ho et al. developed a novel so-called super ink jet printing (SIJP) system which had printing features of sub-micron dimensions and high precision [86]. In the SIJP system, the traditional drop ejection system, such as piezoelectric or thermal actuators, was replaced by 
electrohydrodynamic actuation, which resulted in droplets with volumes as small as $1 \mathrm{fL}$, and sub-micron lateral feature sizes. During the printing process, the small volume of droplets could cause the droplet solvent to evaporate fast, so that the viscosity of the ink increased dramatically. Meanwhile, the convective flow or surface tension effects could be minimized during the deposition process. In this study [32], the ink was prepared by mixture of silver nanopaste with an average size of $24 \mathrm{~nm}$ and $\mathrm{n}$-tetradecane with suitable viscosity for direct ink printing. With the purpose of getting high conductivity and dense structures of printed silver, the printed nanopaste was sintered at $250{ }^{\circ} \mathrm{C}$ for $1 \mathrm{~h}$. Two staggered arrays of pillars were then printed by SIJP on a silver electrode pad $(3 \mathrm{~mm} \times 3 \mathrm{~mm})$. After that, a pair of 3D-printed silver structures was submerged into the aqueous electrolyte, which consisted of $10 \mathrm{M} \mathrm{KOH}$ with $57 \mathrm{~g} \mathrm{~L}^{-1}$ dispersed zinc oxide $(\mathrm{ZnO})$ powder with a particle size of $30 \mathrm{~nm}$.

The electrochemical performance exhibited two obvious anodic peaks at $1.73 \mathrm{~V}$ and 1.81 $\mathrm{V}$, which indicated that monovalent and divalent oxides of silver were formed at the positive electrode. Three cathodic peaks were detected at $1.82 \mathrm{~V}, 1.5 \mathrm{~V}$ and $1.3 \mathrm{~V}$ and the magnitudes of all peaks decreased after few cycles except the peak at $1.82 \mathrm{~V}$. This phenomenon suggested that the stability of the formed silver oxides was changing with increasing number of cycles. A constant current experiment for silver electrodes showed that the discharge capacity decreased fast during the first seven cycles. The galvanostatic discharge performance of two microbatteries, one was prepared by using SIJP printed pillar electrodes, and the other one was prepared by using SIJP printed electrode pads. As a result, the areal charge capacity increased about $60 \%$ at current of $0.1 \mathrm{~mA}$ for the pillared electrodes due to their larger volume and surface area. The energy density of pillared electrodes was $3.95 \mathrm{mWh} \mathrm{cm}^{-2}$, and it was larger than planar electrodes of $2.33 \mathrm{mWh} \mathrm{cm}^{-2}$ [32]. 


\subsection{D direct ink writing zinc-manganese dioxide micro-battery}

Though the performance of 3D zinc-based micro-battery has significant improvement compared to the traditional zinc-based battery, it still suffered from some difficulties in achieving repeated re-chargeability predominantly [87]. The reasons include the shape change in zinc electrodes, dendrite formation and the solubility of reaction products within the liquid electrolyte [88]. In order to minimize these issues, ionic liquid gel electrolyte was used by Ho et al. in the $\mathrm{Zn}-\mathrm{MnO}_{2}$ micro-battery [87]. Room temperature ionic liquids are molten salts at room temperature with the properties that include large electrochemical and temperature stabilities, high ionic conductivity, and negligible vapor pressure [89, 90]. Ionic liquids can be incorporated into polymers to form a gel electrolyte for energy storage device applications with solid-like mechanical strength and liquid-like ion transport properties [87]. In a work [87], the zinc electrode was prepared by mixing $95 \mathrm{wt} \%$ zinc powder with particle size of $50 \mathrm{~nm}$ and $5 \mathrm{wt} \%$ poly (vinylidene fluoride-hexafluoropropylene) solution (PVDF-HFP) which was prepared by adding one part of polymer powder in ten parts of n-methyl-2-pyrrolidone (NMP) solvent, the manganese dioxide $\left(\mathrm{MnO}_{2}\right)$ electrode contain $90 \mathrm{wt} \% \mathrm{MnO}_{2}$ powder, $6 \mathrm{wt} \%$ acetylene black conductive filler and $4 \mathrm{wt} \%$ PVDF-HFP solution. The gel electrolyte was composed of equal weight ratios of PVDF-HFP and $0.5 \mathrm{M}$ solution of zinc trifluoromethanesulfonate $\left(\mathrm{Zn}^{+} \mathrm{Tf}^{-}\right)$salt dissolved in 1-butyl-3-methylimidazolium trifluoromethanesulfonate (BMIM+Tf) ionic liquid. Fig. 8(a) shows the viscosity behaviors of electrode, gel electrolyte and pure ionic liquid as a function of shear rate. After the ionic liquid was combined with polymer to form a gel, the viscosity had a significant improvement compared with the pure ionic liquid. The viscosity of the slurry decreased when the shear rate increased. The $\mathrm{Zn}-\mathrm{MnO}_{2}$ micro-battery was fabricated 
following the process schematic seen in Fig. 8(b). The electrodes were fabricated by a needle with $330 \mu \mathrm{m}$ inner diameter and then dried at $60{ }^{\circ} \mathrm{C}$ for 20 mins. The gel electrolyte was also prepared by the same needles. Nickel foil worked as the current collector for the $\mathrm{MnO}_{2}$ electrode as well as the substrate for printing. Zn slurry served as the electrode and its own current collector. Fig. 8(c) presents a sandwich structure of $\mathrm{Zn}-\mathrm{MnO}_{2}$ micro-battery [87].

(a)

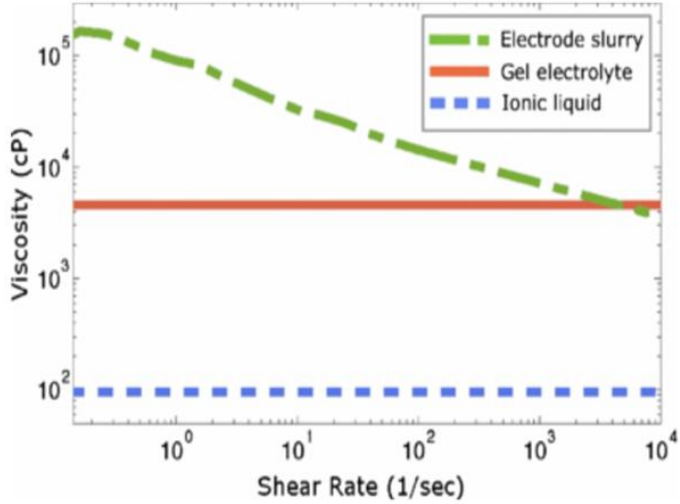

(d)

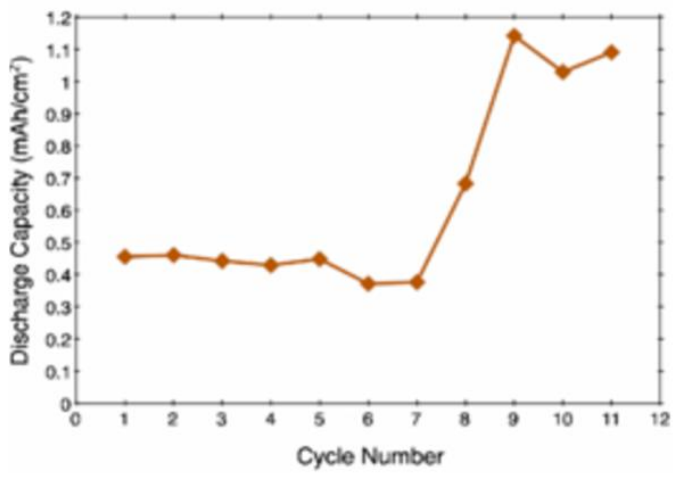

(b)

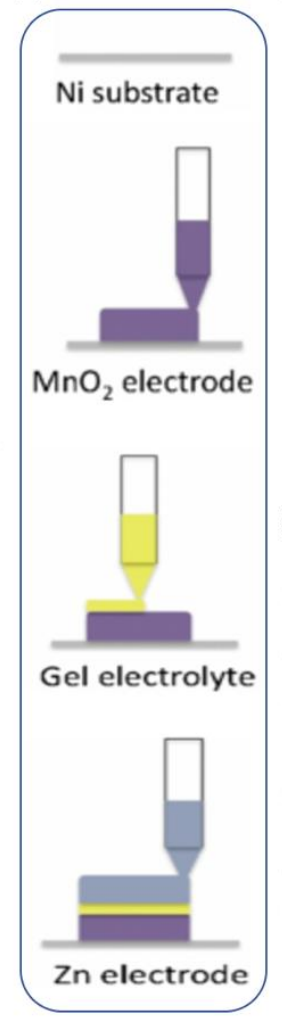

(c)

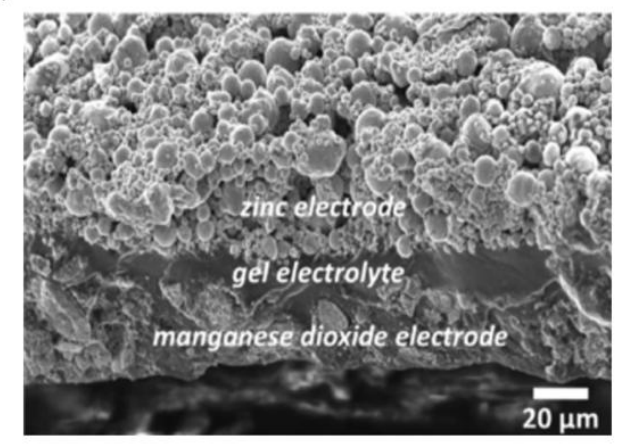

(e)

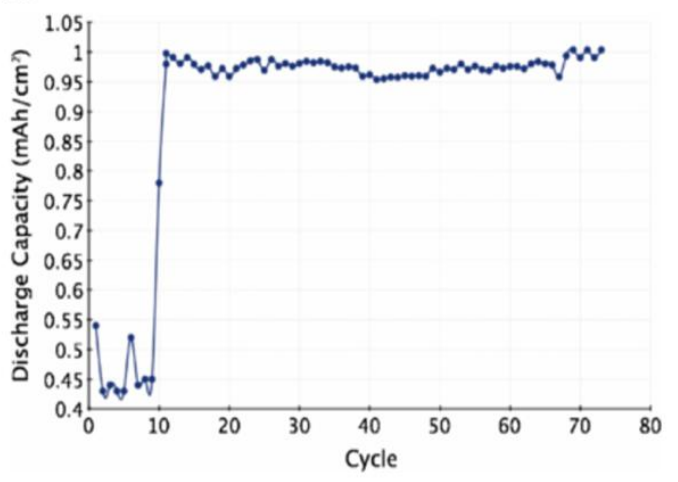

Fig. 8. (a) Viscosity behavior of the electrode (mesocarbon microbead powder and PVDF-HFP in NMP), gel electrolyte (PVDF-HFP and $\mathrm{Zn}^{+} \mathrm{Tf}^{-}$in $\mathrm{BMIM}^{+} \mathrm{Tf}$ ), pure ionic liquid (BMIM${ }^{+} \mathrm{Tf}$ ), 
(b) Schematic illustration of $\mathrm{Zn}-\mathrm{MnO}_{2}$ micro-battery, (c) Cross-section of $\mathrm{Zn}-\mathrm{MnO}_{2}$ microbattery, (d) Cycling behavior of $\mathrm{Zn}-\mathrm{MnO}_{2}$ micro-battery after 10 cycles, (e) Discharge capacity of $\mathrm{Zn}-\mathrm{MnO}_{2}$ micro-battery over 70 cycles. With reprint permission from Ref [87].

The electrochemical performance is shown in the Fig. 8(d-e). In general, the initial capacity of traditional $\mathrm{Zn}-\mathrm{MnO}_{2}$ cell was around $250 \mathrm{mAh} \mathrm{g}{ }^{-1}$ in a $10 \mathrm{wt} \% \mathrm{KOH}$ electrolyte, and only $31 \%$ capacity remaining after 24 cycles [91]. After $\mathrm{KOH}$ was replaced by ionic liquid gel electrolyte, there is a significant improvement in performance. Fig. 8(d) demonstrates by using discharge rates of $\mathrm{C} / 3$ or smaller, there was a dramatic capacity increase between cycles 7 and 9 , and the capacity became stable with further cycling. This could be explained by the activation behavior of the $\mathrm{MnO}_{2}$ electrode. The $\mathrm{MnO}_{2}$ electrode experienced an activation process induced by the intercalation of $\mathrm{Zn}$ ions, which caused the physical form of the material to change from crystalline to amorphous. This reference did not provide enough evidence to prove this phenomenon, and further characterization should be carried out. Fig. 8(e) illustrates that the discharge capacity plateaus of $\mathrm{Zn}-\mathrm{MnO}_{2}$ micro-battery appeared after 15 cycles and stayed at $\sim 0.98 \mathrm{~mA} \mathrm{~h} \mathrm{~cm}^{-2}$ for the following cycles. The energy density was about $1.2 \mathrm{~mW} \mathrm{~h} \mathrm{~cm}{ }^{-2}$ [87]. From the performance of $\mathrm{Zn}-\mathrm{MnO}_{2}$ micro-battery, it became apparent that $\mathrm{Zn}$ had a great compatibility with the gel electrolyte and good reversible behavior when cycled against the $\mathrm{MnO}_{2}$ electrode.

\section{Summary and Outlook}

Research on electrochemical storage devices based on 3D direct ink writing techniques has been reviewed here by highlighting advances from different research groups. We elaborated 
on the electrochemical storage principles of supercapacitors and batteries and the comparison of devices with 2D and 3D structure 3D direct ink writing provides a new method to fabricate electrodes for energy storage devices. The surface area of devices increases significantly by using 3D printing techniques, which result in the capacitance improvement. Nevertheless, there are some limitations of 3D printing technologies that still need to be addressed. So far, only a few materials can be applied to 3D printing techniques. Most active materials applied in energyrelated applications are inorganic materials, and several additives are required to add into the inks to increase ink viscosity. However, these additives may change the properties of active materials and influence the final performance of devices. Moreover, 3D-printed electrodes with porous structure are vulnerable due to their poor mechanical properties. Even though carbon materials are commonly used in 3D printing techniques today, further research on advanced materials having high viscosity, small particle size, and excellent mechanical properties need to be continued. In addition, a big issue in today's energy storage devices is the liquid electrolyte typically used for providing sufficient ionic conductivity. However, safety of liquid electrolytes is a big concern due to possible leakage of liquid electrolyte during the thermal stress. The direct ink writing technique offers an effective way to fabricate solid-state electrolyte with flexible shapes. The overall thickness of the devices can be minimized and fit for different applications once the solid-state electrolyte is applied. For the future research, the selection of materials for electrodes and electrolyte should be optimized in 3D printing system, and the electrochemical performance of devices with high rate capability and long cycle life should be improved. 3D solid state electrolyte energy storage devices consisting of 3D structure electrodes and solid state electrolyte fabricated by the convenient 3D direct ink writing will become the next generation of energy device with the properties of light weight, high capacity, and better safety improved. 


\section{Acknowledgments}

This work is financially supported from the SUNY Network of Excellence in Materials and Advanced Manufacturing program along with the Sustainable Manufacturing and Advanced Robotics Technology (SMART) Community of Excellence program at the University at Buffalo. G. Wu also acknowledges the funding from National Science Foundation (CBET-1604392) for the effort in fabricating solid-state electrolytes for batteries.

\section{References}

[1] K. Chen, D. Xue, Materials chemistry toward electrochemical energy storage, Journal of Materials Chemistry A, 4 (2016) 7522-7537.

[2] X. Luo, J. Wang, M. Dooner, J. Clarke, Overview of current development in electrical energy storage technologies and the application potential in power system operation, Applied Energy, 137 (2015) 511-536.

[3] M. Winter, R.J. Brodd, What are batteries, fuel cells, and supercapacitors?, Chemical Reviews, 104 (2004) 4245-4270.

[4] O. Haas, E.J. Cairns, Electrochemical energy storage, Physical Chemistry, 95 (1999) 163198.

[5] D.C. Johnson, A.L. Prieto, Three-dimensional Lithium-Ion batteries with interdigitated electrodes, In Proc. SPIE, 8728 (2013) 872805-872810. 
[6] A. Ruddell, Investigation on storage technologies for intermittent renewable energies: evaluation and recommended R\&D strategy: storage technology report, WP-ST6 Flywheel, Chilton, Didcot, UK, (2003).

[7] I. Hadjipaschalis, A. Poullikkas, V. Efthimiou, Overview of current and future energy storage technologies for electric power applications, Renewable and Sustainable Energy Reviews, 13 (2009) 1513-1522.

[8] L. Feng, Y. Zhu, H. Ding, C. Ni, Recent progress in nickel based materials for high performance pseudocapacitor electrodes, Journal of Power Sources, 267 (2014) 430-444.

[9] F. Yao, D.T. Pham, Y.H. Lee, Carbon-based materials for Lithium-Ion batteries, electrochemical capacitors, and their hybrid devices, ChemSusChem, 8 (2015) 2284-2311.

[10] Y. Wang, Z. Shi, Y. Huang, Y. Ma, C. Wang, M. Chen, Y. Chen, Supercapacitor devices based on graphene materials, Journal of Physical Chemistry C, 113 (2009) 13103-13107.

[11] S. Ye, J. Feng, P. Wu, Deposition of three-dimensional graphene aerogel on nickel foam as a binder-free supercapacitor electrode, ACS Applied Materials \& Interfaces, 5 (2013) $7122-7129$.

[12] H. Sheng, M. Wei, A. D’Aloia, G. Wu, Heteroatom polymer-derived 3D high-surface-area and mesoporous graphene sheet-like carbon for supercapacitors, ACS Applied Materials \& Interfaces, 8 (2016) 30212-30224.

[13] C. Liu, Z. Yu, D. Neff, A. Zhamu, B.Z. Jang, Graphene-based supercapacitor with an ultrahigh energy density, Nano Letters, 10 (2010) 4863-4868.

[14] A. Shukla, S. Sampath, K. Vijayamohanan, Electrochemical supercapacitors: energy storage beyond batteries, Current Science, 79 (2000) 1656-1661. 
[15] D.W. Wang, F. Li, M. Liu, G.Q. Lu, H.M. Cheng, 3D aperiodic hierarchical porous graphitic carbon material for high-rate electrochemical capacitive energy storage, Angewandte Chemie International Edition, 47 (2008) 373-376.

[16] K. Sun, T.-S. Wei, B.Y. Ahn, J.Y. Seo, S.J. Dillon, J.A. Lewis, 3D printing of interdigitated Li-Ion microbattery architectures, Advanced Materials, 25 (2013) 4539-4543.

[17] T.S. Arthur, D.J. Bates, N. Cirigliano, D.C. Johnson, P. Malati, J.M. Mosby, E. Perre, M.T. Rawls, A.L. Prieto, B. Dunn, Three-dimensional electrodes and battery architectures, MRS Bulletin, 36 (2011) 523-531.

[18] J. Newman, K.E. Thomas-Alyea, Electrochemical systems, John Wiley \& Sons, 2012. ISBN 0-471-47756-7.

[19] D.R. Rolison, J.W. Long, J.C. Lytle, A.E. Fischer, C.P. Rhodes, T.M. McEvoy, M.E. Bourg, A.M. Lubers, Multifunctional 3D nanoarchitectures for energy storage and conversion, Chemical Society Reviews, 38 (2009) 226-252.

[20] M. Beidaghi, Y. Gogotsi, Capacitive energy storage in micro-scale devices: recent advances in design and fabrication of micro-supercapacitors, Energy \& Environmental Science, 7 (2014) 867-884.

[21] J.A. Lewis, Direct ink writing of 3D functional materials, Advanced Functional Materials, 16 (2006) 2193-2204.

[22] N. Anscombe, Direct laser writing, Nature Photonics, 4 (2010) 22-23.

[23] J.H. Jang, C.K. Ullal, M. Maldovan, T. Gorishnyy, S. Kooi, C. Koh, E.L. Thomas, 3D micro-and nanostructures via interference lithography, Advanced Functional Materials, 17 (2007) 3027-3041. 
[24] I. Bita, T. Choi, M.E. Walsh, H.I. Smith, E.L. Thomas, Large-area 3D nanostructures with octagonal quasicrystalline symmetry via phase-mask lithography, Advanced Materials, 19 (2007) 1403-1407.

[25] H.-Y. Ko, J. Park, H. Shin, J. Moon, Rapid self-assembly of monodisperse colloidal spheres in an ink-jet printed droplet, Chemistry of Materials, 16 (2004) 4212-4215.

[26] J.A. Lewis, G.M. Gratson, Direct writing in three dimensions, Materials Today, 7 (2004) 32-39.

[27] S.A. Khaled, J.C. Burley, M.R. Alexander, C.J. Roberts, Desktop 3D printing of controlled release pharmaceutical bilayer tablets, International Journal of Pharmaceutics, 461 (2014) $105-111$.

[28] K. Hon, L. Li, I. Hutchings, Direct writing technology-advances and developments, CIRP Annals-Manufacturing Technology, 57 (2008) 601-620.

[29] D. Therriault, S.R. White, J.A. Lewis, Chaotic mixing in three-dimensional microvascular networks fabricated by direct-write assembly, Nature Materials, 2 (2003) 265-271 .

[30] D.W. Hutmacher, T. Schantz, I. Zein, K.W. Ng, S.H. Teoh, K.C. Tan, Mechanical properties and cell cultural response of polycaprolactone scaffolds designed and fabricated via fused deposition modeling, Journal of Biomedical Materials Research Part A, 55 (2001) 203-216.

[31] S.L. Morissette, J.A. Lewis, P.G. Clem, J. Cesarano, D.B. Dimos, Direct-write fabrication of $\mathrm{Pb}(\mathrm{Nb}, \mathrm{Zr}, \mathrm{Ti}) \mathrm{O} 3$ devices: influence of paste rheology on print morphology and component properties, Journal of the American Ceramic Society, 84 (2001) 2462-2468. 
[32] C.C. Ho, K. Murata, D.A. Steingart, J.W. Evans, P.K. Wright, A super ink jet printed zincsilver 3D microbattery, Journal of Micromechanics and Microengineering, 19 (2009) 094013.

[33] K.A. Seerden, N. Reis, J.R. Evans, P.S. Grant, J.W. Halloran, B. Derby, Ink-jet printing of wax-based alumina suspensions, Journal of the American Ceramic Society, 84 (2001) 2514-2520.

[34] J.A. Lewis, J.E. Smay, J. Stuecker, J. Cesarano, Direct ink writing of three-dimensional ceramic structures, Journal of the American Ceramic Society, 89 (2006) 3599-3609.

[35] Q. Xu, Y. Lv, C. Dong, T.S. Sreeprased, A. Tian, H. Zhang, Y. Tang, Z. Yu, N. Li, Threedimensional micro/nanoscale architectures: fabrication and applications, Nanoscale, 7 (2015) 10883-10895.

[36] J.R. Raney, J.A. Lewis, Printing mesoscale architectures, MRS Bulletin, 40 (2015) 943-950.

[37] K. Fu, Y. Wang, C. Yan, Y. Yao, Y. Chen, J. Dai, S. Lacey, Y. Wang, J. Wan, T. Li, Graphene oxide-based electrode inks for 3D-printed Lithium-Ion batteries, Advanced Materials, 28 (2016) 2587-2594.

[38] K. Fu, Y. Yao, J. Dai, L. Hu, Progress in 3D printing of carbon materials for energy-related applications, Advanced Materials, (2016) DIO:10.1002/adma.201603486.

[39] C. Zhu, T. Liu, F. Qian, T.Y.-J. Han, E.B. Duoss, J.D. Kuntz, C.M. Spadaccini, M.A. Worsley, Y. Li, Supercapacitors based on three-dimensional hierarchical graphene aerogels with periodic macropores, Nano Letters, (2016) 3448-3456.

[40] X. Huang, Z. Yin, S. Wu, X. Qi, Q. He, Q. Zhang, Q. Yan, F. Boey, H. Zhang, Graphene-based materials: synthesis, characterization, properties, and applications, Small, 7 (2011) 1876-1902. 
[41] X. Li, W. Cai, J. An, S. Kim, J. Nah, D. Yang, R. Piner, A. Velamakanni, I. Jung, E. Tutuc, Large-area synthesis of high-quality and uniform graphene films on copper foils, Science, 324 (2009) 1312-1314.

[42] X. Cao, Y. Shi, W. Shi, G. Lu, X. Huang, Q. Yan, Q. Zhang, H. Zhang, Preparation of novel 3D graphene networks for supercapacitor applications, Small, 7 (2011) 3163-3168.

[43] Y. Xu, Z. Lin, X. Huang, Y. Liu, Y. Huang, X. Duan, Flexible solid-state supercapacitors based on three-dimensional graphene hydrogel films, ACS Nano, 7 (2013) 4042-4049.

[44] X. Zhang, Z. Sui, B. Xu, S. Yue, Y. Luo, W. Zhan, B. Liu, Mechanically strong and highly conductive graphene aerogel and its use as electrodes for electrochemical power sources, Journal of Materials Chemistry, 21 (2011) 6494-6497.

[45] Y. Zhao, J. Liu, Y. Hu, H. Cheng, C. Hu, C. Jiang, L. Jiang, A. Cao, L. Qu, Highly compression-tolerant supercapacitor based on polypyrrole-mediated graphene foam electrodes, Advanced Materials, 25 (2013) 591-595.

[46] L.L. Zhang, X. Zhao, M.D. Stoller, Y. Zhu, H. Ji, S. Murali, Y. Wu, S. Perales, B. Clevenger, R.S. Ruoff, Highly conductive and porous activated reduced graphene oxide films for high-power supercapacitors, Nano Letters, 12 (2012) 1806-1812.

[47] J. Li, X. Wang, Q. Huang, S. Gamboa, P. Sebastian, Studies on preparation and performances of carbon aerogel electrodes for the application of supercapacitor, Journal of Power Sources, 158 (2006) 784-788.

[48] Q. Zhang, F. Zhang, S.P. Medarametla, H. Li, C. Zhou, D. Lin, 3D printing of graphene aerogels, Small, 12 (2016) 1702-1708.

[49] O. Okay, General properties of hydrogels, hydrogel sensors and actuators, Springer Berlin Heidelberg, 6 (2009) 1-14. 
[50] J. Fricke, T. Tillotson, Aerogels: production, characterization, and applications, Thin Solid Films, 297 (1997) 212-223.

[51] L.W. Hrubesh, Aerogel applications, Journal of Non-Crystalline Solids, 225 (1998) 335342.

[52] C. Zhu, T.Y.-J. Han, E.B. Duoss, A.M. Golobic, J.D. Kuntz, C.M. Spadaccini, M.A. Worsley, Highly compressible 3D periodic graphene aerogel microlattices, Nature Communications, 6 (2015) 6962-6970.

[53] C. Wang, K. Takei, T. Takahashi, A. Javey, Carbon nanotube electronics-moving forward, Chemical Society Reviews, 42 (2013) 2592-2609.

[54] C.A. Milroy, S. Jang, T. Fujimori, A. Dodabalapur, A. Manthiram, Inkjet-printed LithiumSulfur microcathodes for all-printed, Integrated Nanomanufacturing, Small, (2017) DOI:10.1002/smll.201603786.

[55] M.-Q. Zhao, X.-F. Liu, Q. Zhang, G.-L. Tian, J.-Q. Huang, W. Zhu, F. Wei, Graphene/single-walled carbon nanotube hybrids: one-step catalytic growth and applications for high-rate Li-S batteries, ACS Nano, 6 (2012) 10759-10769.

[56] J.W. Long, D.R. Rolison, Architectural design, interior decoration, and three-dimensional plumbing en route to multifunctional nanoarchitectures, Accounts of Chemical Research, 40 (2007) 854-862.

[57] C. Milroy, A. Manthiram, Printed microelectrodes for scalable, high-areal-capacity lithium-sulfur batteries, Chemical Communications, 52 (2016) 4282-4285.

[58] L. Zeng, F. Pan, W. Li, Y. Jiang, X. Zhong, Y. Yu, Free-standing porous carbon nanofibers-sulfur composite for flexible Li-S battery cathode, Nanoscale, 6 (2014) 95799587. 
[59] H. Meng, G. Li, A review of stimuli-responsive shape memory polymer composites, Polymer, 54 (2013) 2199-2221.

[60] Q. Meng, J. Hu, A review of shape memory polymer composites and blends, Composites Part A: Applied Science and Manufacturing, 40 (2009) 1661-1672.

[61] L.T. Le, M.H. Ervin, H. Qiu, B.E. Fuchs, W.Y. Lee, Graphene supercapacitor electrodes fabricated by inkjet printing and thermal reduction of graphene oxide, Electrochemistry Communications, 13 (2011) 355-358.

[62] W. Huang, Y. Wu, L. Qiu, C. Dong, J. Ding, D. Li, Tuning rheological performance of silica concentrated shear thickening fluid by using graphene oxide, Advances in Condensed Matter Physics, 2015 (2015) 1-7.

[63] M.A. Worsley, T.Y. Olson, J.R. Lee, T.M. Willey, M.H. Nielsen, S.K. Roberts, P.J. Pauzauskie, J. Biener, J.H. Satcher Jr, T.F. Baumann, High surface area, sp2-cross-linked three-dimensional graphene monoliths, Journal of Physical Chemistry Letters, 2 (2011) 921-925.

[64] M.A. Worsley, S. Charnvanichborikarn, E. Montalvo, S.J. Shin, E.D. Tylski, J.P. Lewicki, A.J. Nelson, J.H. Satcher, J. Biener, T.F. Baumann, Toward macroscale, isotropic carbons with graphene-sheet-like electrical and mechanical properties, Advanced Functional Materials, 24 (2014) 4259-4264.

[65] M.A. Worsley, S.O. Kucheyev, H.E. Mason, M.D. Merrill, B.P. Mayer, J. Lewicki, C.A. Valdez, M.E. Suss, M. Stadermann, P.J. Pauzauskie, Mechanically robust 3D graphene macroassembly with high surface area, Chemical Communications, 48 (2012) 8428-8430.

[66] I. Smallwood, Handbook of organic solvent properties, Butterworth-Heinemann, 2012. ISBN: 978-0-080-52378-1. 
[67] G. Wang, H. Wang, X. Lu, Y. Ling, M. Yu, T. Zhai, Y. Tong, Y. Li, Solid-state supercapacitor based on activated carbon cloths exhibits excellent rate capability, Advanced Materials, 26 (2014) 2676-2682.

[68] G. Yu, X. Xie, L. Pan, Z. Bao, Y. Cui, Hybrid nanostructured materials for highperformance electrochemical capacitors, Nano Energy, 2 (2013) 213-234.

[69] P. Yang, W. Mai, Flexible solid-state electrochemical supercapacitors, Nano Energy, 8 (2014) 274-290.

[70] Y.J. Kang, H. Chung, C.-H. Han, W. Kim, All-solid-state flexible supercapacitors based on papers coated with carbon nanotubes and ionic-liquid-based gel electrolytes, Nanotechnology, 23 (2012) 065401-065407.

[71] S. Stankovich, D.A. Dikin, G.H. Dommett, K.M. Kohlhaas, E.J. Zimney, E.A. Stach, R.D. Piner, S.T. Nguyen, R.S. Ruoff, Graphene-based composite materials, Nature, 442 (2006) 282-286.

[72] J. Li, F. Ye, S. Vaziri, M. Muhammed, M.C. Lemme, M. Östling, Efficient inkjet printing of graphene, Advanced Materials, 25 (2013) 3985-3992.

[73] K. Chi, Z. Zhang, J. Xi, Y. Huang, F. Xiao, S. Wang, Y. Liu, Freestanding graphene paper supported three-dimensional porous graphene-polyaniline nanocomposite synthesized by inkjet printing and in flexible all-solid-state supercapacitor, ACS Applied Materials \& Interfaces, 6 (2014) 16312-16319.

[74] P.S. Waggoner, H.G. Craighead, Micro-and nanomechanical sensors for environmental, chemical, and biological detection, Lab on a Chip, 7 (2007) 1238-1255.

[75] C. Zhang, J. Xu, W. Ma, W. Zheng, PCR microfluidic devices for DNA amplification, Biotechnology Advances, 24 (2006) 243-284. 
[76] S. Spearing, Materials issues in microelectromechanical systems (MEMS), Acta Materialia, 48 (2000) 179-196.

[77] S. Roundy, P.K. Wright, J.M. Rabaey, Introduction, in: Energy scavenging for wireless sensor networks, Springer Science \& Business Media, 2004. ISBN: 978-1-4615-0485-6.

[78] Y. Lin, P. Alexandridis, Cosolvent effects on the micellization of an amphiphilic siloxane graft copolymer in aqueous solutions, Langmuir, 18 (2002) 4220-4231.

[79] J. Lewis, S. Dillon, K. Sun, B.Y. Ahn, T.-s. Wei, Three-dimensional (3D) electrode architecture for microbattery, US Patent Application No. 14/890,072.

[80] Y. Su, H. Wei, R. Gao, Z. Yang, J. Zhang, Z. Zhong, Y. Zhang, Exceptional negative thermal expansion and viscoelastic properties of graphene oxide paper, Carbon, 50 (2012) 2804-2809.

[81] C. Bardpho, P. Rattanarat, W. Siangproh, O. Chailapakul, Ultra-high performance liquid chromatographic determination of antioxidants in teas using inkjet-printed graphenepolyaniline electrode, Talanta, 148 (2016) 673-679.

[82] S.H. Huh, Thermal reduction of graphene oxide, INTECH Open Access Publisher, 2011. ISBN: 978-953-307-217-3.

[83] A. Paolella, G. Bertoni, E. Dilena, S. Marras, A. Ansaldo, L. Manna, C. George, Redox centers evolution in phospho-olivine type ( $\mathrm{LiFeO}$. 5MnO. 5 PO4) nanoplatelets with uniform cation distribution, Nano Letters, 14 (2014) 1477-1483.

[84] J. Hu, Y. Jiang, S. Cui, Y. Duan, T. Liu, H. Guo, L. Lin, Y. Lin, J. Zheng, K. Amine, 3D-printed cathodes of LiMn1- xFexPO4 nanocrystals achieve both ultrahigh rate and high capacity for advanced Lithium-Ion battery, Advanced Energy Materials, 6 (2016) 1228.

[85] D. Linden, Handbook of batteries, Fuel and Energy Abstracts, 36 (1995) 265. 
[86] K. Murata, J. Matsumoto, A. Tezuka, Y. Matsuba, H. Yokoyama, Super-fine ink-jet printing: toward the minimal manufacturing system, Microsystem Technologies, 12 (2005) $1-2$.

[87] C.C. Ho, J.W. Evans, P.K. Wright, Direct write dispenser printing of a zinc microbattery with an ionic liquid gel electrolyte, Journal of Micromechanics and Microengineering, 20 (2010) 104009.

[88] G.G. Kumar, S. Sampath, Electrochemical characterization of a zinc-based gel-polymer electrolyte and its application in rechargeable batteries, Journal of The Electrochemical Society, 150 (2003) 608-615.

[89] S.A. Forsyth, J.M. Pringle, D.R. MacFarlane, Ionic liquids-an overview, Australian Journal of Chemistry, 57 (2004) 113-119.

[90] Z. He, P. Alexandridis, Nanoparticles in ionic liquids: interactions and organization, Physical Chemistry Chemical Physics, 17 (2015) 18238-18261.

[91] N.D. Ingale, J.W. Gallaway, M. Nyce, A. Couzis, S. Banerjee, Rechargeability and economic aspects of alkaline zinc-manganese dioxide cells for electrical storage and load leveling, Journal of Power Sources, 276 (2015) 7-18. 